\title{
Defining plant growth promoting rhizobacteria molecular and biochemical networks in beneficial plant-microbe interactions
}

\author{
Amanda Rosier • Flávio H. V. Medeiros • Harsh P. Bais
}

Received: 27 September 2017 / Accepted: 8 May 2018/Published online: 21 May 2018

(C) Springer International Publishing AG, part of Springer Nature 2018

\begin{abstract}
Background Our knowledge of plant beneficial bacteria in the rhizosphere is rapidly expanding due to intense interest in utilizing these types of microbes in agriculture. Laboratory and field studies consistently document the growth, health and protective benefits conferred to plants by applying plant growth promoting rhizobacteria (PGPR). PGPR exert their influence on other species, including plants, in the rhizosphere by producing a wide array of extracellular molecules for communication and defense.

Scope The types of PGPR molecular products are characteristically diverse, and the mechanisms by which they are acting on the plant are only beginning to be understood. While plants may contribute to shape their microbiome, it is these bacterial products which induce beneficial responses in plants. PGPR extracellular products can directly stimulate plant genetic and molecular
\end{abstract}

Responsible Editor: Philippe Hinsinger.

A. Rosier $\cdot$ H. P. Bais

Department of Plant and Soil Sciences, University of Delaware,

Newark, DE, USA

A. Rosier $(\bowtie) \cdot$ H. P. Bais $(\bowtie)$

Delaware Biotechnology Institute, University of Delaware,

Newark, DE, USA

e-mail: amandaro@udel.edue-mail: hbais@udel.edu

F. H. V. Medeiros

Department of Plant Pathology, Campus Universitário,

Universidade Federal de Lavras, CP 3037, Lavras, MG

37200-000, Brazil pathways, leading to increases in plant growth and induction of plant resistance and tolerance. This review will discuss known PGPR-derived molecules, and how these products are implicated in inducing plant beneficial outcomes through complex plant response mechanisms.

Conclusions In order to move PGPR research to the next level, it will be important to describe and document the genetic and molecular mechanisms employed in these interactions. In this way, we will be able to restructure and harness these mechanisms in a way that allows for broad-based applications in agriculture. A greater depth of understanding of how these PGPR molecules are acting on the plant will allow more effective development of rhizobacterial applications in the field.

Keywords Agriculture - Exo-metabolite - Nutrition · Plant Plant defense $\cdot$ Plant growth promoting rhizobacteria $\cdot$ PGPR $\cdot$ Resistance $\cdot$ Rhizosphere . Symbiosis

$\begin{array}{ll}\text { Abbreviations } \\ \text { PGPR } & \text { Plant growth promoting rhizobacteria } \\ \text { NOD } & \text { Nodulation factors } \\ \text { NF } & \text { Nod factors } \\ \text { LCO } & \text { Lipo-chitooligosaccharides } \\ \text { LPS } & \text { Lipopolysaccharides } \\ \text { EPS } & \text { Exopolysaccharides } \\ \text { ACC } & \text { 1-aminocyclopropane-1-carboxylate } \\ \text { deaminase } & \text { deaminase } \\ \text { MAMP/ } & \text { Microbial/Pathogen associated molecu- } \\ \text { PAMP } & \text { lar patterns }\end{array}$




$\begin{array}{ll}\text { MTI/PTI } & \text { MAMP/PAMP triggered immunity } \\ \text { ETI } & \text { Effector triggered immunity } \\ \text { IAA } & \text { Indole acetic acid } \\ \text { GA } & \text { Gibberellic acid } \\ \text { ET } & \text { Ethylene } \\ \text { ABA } & \text { Abscisic acid } \\ \text { JA } & \text { Jasmonic acid } \\ \text { SA } & \text { Salicylic acid } \\ \text { SAR } & \text { Systemic acquired resistance } \\ \text { ISR } & \text { Induced systemic resistance } \\ \text { VOC } & \text { Volatile organic compound } \\ \text { BVC } & \text { Bacterial volatile compound } \\ \text { QS } & \text { Quorum sensing } \\ \text { AHL } & \text { N-acyl homoserine lactone } \\ \text { CDP } & \text { Cyclodipeptide } \\ \text { DAPG } & \text { 2,4-diacetylphloroglucinol } \\ \text { cLP } & \text { Cyclic lipopeptide } \\ \text { DMDS } & \text { Dimethyl disulfide }\end{array}$

\section{Introduction}

With the advancements of genetic tools and technologies, the 'black box' analogy as applied to our knowledge of the microbial residents in the soil and rhizosphere is rapidly becoming more transparent. We are at a point in time where rhizosphere microbiome studies have the potential to be meaningfully applied. The field of rhizosphere research is awash in metagenomics and metabolomics data, identifying genes, functional taxonomic units and metabolites of microbial origin (Paterson et al. 2017). A multitude of investigations have identified specific plant growth promoting rhizobacteria (PGPR) to the species and strain level that confer observable benefits to their plant host; and there is confirmed evidence of PGPR influence on plant traits (Friesen et al. 2011). Agricultural manufacturers are investing their research efforts on developing targeted combinations of different microbes in their formulations that best provide benefits for individual crops and environment (Dessaux et al. 2016)

These examinations provide a valuable framework for understanding the taxonomy of PGPRs, as well as establishing that PGPRs are conferring measurable benefits to the plant. However, PGPR research is primed for the next step; it is time to gain a complete understanding of the mechanistic and genetic basis of microbial activities directly influencing beneficial plant genetic and physiological responses. Environmental conditions in the field are becoming increasingly more unpredictable, exposing crops to catastrophic weather events, shifts in seasonality and increasing pest and pathogen pressures. High-throughput screening methods used for identifying, selecting and bringing the appropriate formulation of micro-organisms to market will not adequately address these inevitable challenges.

The true power in understanding the root-associated microbiome will be in detecting the chemical and genetic mechanisms by which plant-specific microbes are inducing beneficial plant outcomes. While global agricultural practitioners have been applying chemicals to crops since the Green Revolution, microbes have been exuding their own substances influencing plant biological systems from the first appearance of higher plants. Indeed, the proliferation of terrestrial plants was facilitated by their microbial partners (Vandenkoornhuyse et al. 2015). As such, we can focus our research on understanding what products rhizosphere microbes are generating, and how they induce plant genetic pathways leading to appropriate responses to environmental challenges. An overview of PGPR products and their known plant/genetic targets discussed in this review can be found in Table 1 . These bacterially derived molecules are diverse in nature and activity, but are typically exometabolites as they function externally from the PGPR.

Through characterizing specific mechanisms, we could 'mimic' them, either by applying bio-manufactured bacterial products or by modifying the plant's genetics to heterologously achieve the same results. This approach could allow for a more reliable product that may be readily deployed in response to rapidly changing environmental conditions (Timmusk et al. 2017). Rhizosphere bacteria-derived chemicals such as rhizobial NOD factors (lipochito-oligosaccharides or LCOs) have been successfully incorporated into crop protection products, enhancing plant growth in both legumes and non-legumes, as well as stimulating plant defense (Subramanian et al. 2016). PGPRs would be an invaluable resource for novel plant defense elicitors which may be more effective than synthetically derived products for crop protection (Bektas and Eulgem 2014; Wiesel et al. 2014).

The application of PGPRs provides benefits to plants through two broad aspects: 1) improving plant nutrient acquisition, and 2) inducing plant resistance. Often, the PGPR or bacterial product will provide cross-protective properties, enhancing, for example, pathogen resistance as well as abiotic resistance through influencing key plant hormone pathways, taking advantage of the natural crosstalk existing between these stress-response pathways 


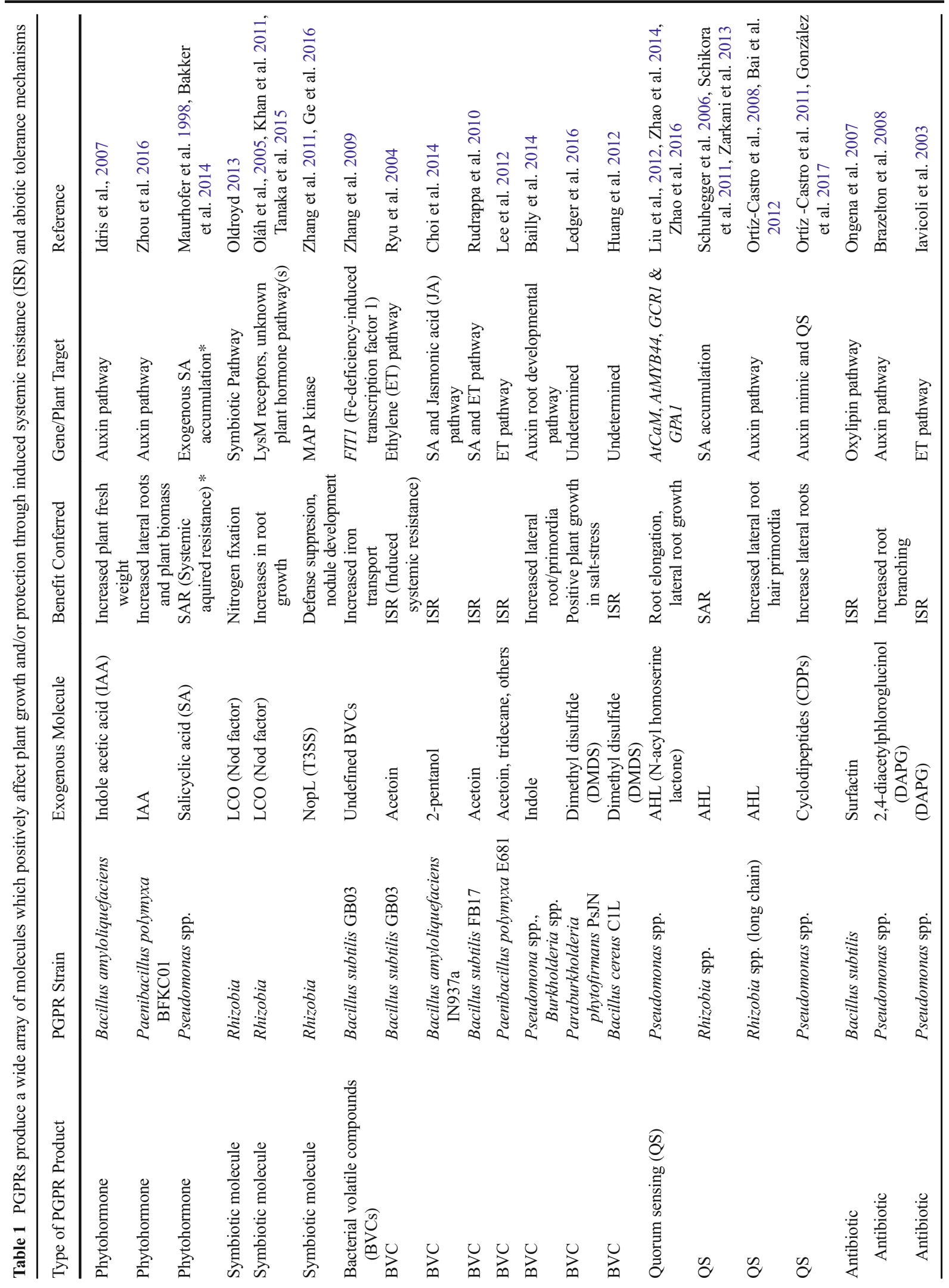


(Fujita et al. 2006). Moreover, PGPR effects on nutrient acquisition can overlap with plant defense pathways through as yet poorly understood crosstalk, often resulting in trade-offs between growth/nutrition and immunity. In two recent studies conducted in nutrient limited conditions, the presence of rhizosphere bacteria (synthetic community 'SynCom') or the product of a PGPR (the siderophore pyoverdine) influenced the plant response, seeming to tip the scales toward nutrient acquisition (phosphate and iron, respectively) rather than pathogen defense (Castrillo et al. 2017; Trapet et al. 2016). In light of this, similar PGPR products will be discussed in the separate aspects in which they influence the plant.

This review will not be covering the multitude of PGPR influences on the soil surrounding the plant root such as phosphorous solubilization (Alori et al. 2017) and assorted means of altering local $\mathrm{pH}$ and physical properties of the rhizosphere (Olanrewaju et al. 2017). The vast collection of bacterial products dictates the limits of this review: it is impossible to cover every molecule that has been reported. Some are already well reviewed such as LPS (Pel and Pieterse 2013), EPS (Gauri et al. 2012), phenazine (Chin-A-Woeng et al. 2003), and ACC deaminase (Glick 2014) and will not be comprehensively addressed in this review. Many beneficial mechanisms of PGPRs also involve influencing the plant to exude a variety of products into the rhizosphere, which indirectly serve to benefit the plant such as recruiting more PGPRs (Rudrappa et al. 2010) or increasing plant release of nutrient scavenging molecules (Zhou et al. 2016). PGPR also engage in a plethora of inter-species anti-microbial, predatory or communal activities that ultimately influence the plant in a beneficial manner, but will not be considered here as direct microbe-plant interactions.

\section{Bacteria enhance plant nutrient acquisition and growth}

Plants co-evolved with microorganisms in symbiotic relationships to successfully colonize terrestrial ecosystems (Werner et al. 2014; Zilber-Rosenberg and Rosenberg 2008). Understanding naturally occurring PGPR beneficial features and interactions could foster the design of agro-systems with decreased fertilizer inputs and sustained or improved plant yields. The most widely explored plant beneficial trait is the mutual symbiotic biological nitrogen fixation by Rhizobia (Udvardi and Poole 2013), but numerous other nutrient acquisition 
machineries have been observed which facilitate plant access to macro-nutrients, micro-nutrients, and carbon allocation.

\section{Nod factors (lipo-chitooligosaccharides (LCOs)}

The mutualistic symbiosis that occurs between rhizobia and their legume hosts is well described, and many genetic and molecular determinants have been uncovered through various model legume-rhizobia systems (Oldroyd 2013). Compounds known as flavonoids are released from legume roots and induce the transcription of rhizobia Nod factors (NF) (Kondorosi et al. 1989). The nod factors (NFs) produced by rhizobia in response to flavonoids are lipo-chitooligosaccharides (LCO), consisting of a chitin core of $\beta 1,4$ linked polymers of $\mathrm{N}$-acetylglucosamine (GlcNAc). The key feature that sets LCOs apart from chitin (an ancient molecule associated with fungi and insect exoskeletons) is the $\mathrm{N}$-acyl moiety consisting of a fatty acid chain varying in length, saturation and substitution groups. These 'decorated' side chains are most likely the primary causal agent conferring specificity between rhizobial strains and plant host targets (Oldroyd 2013).

LCOs are implicated in plant growth promotional activities that span from the classic instigation of mutualistic symbiosis, to altering plant hormone regimes leading to improved photosynthesis and increased resistance to biotic and abiotic challenges (Khan et al. 2008; Mitra and Long 2004; Rey et al. 2013). The touchstone of this intimate relationship between rhizobial LCOs and plants lies in the direct plant perception of the bacterial signal molecule. Plant receptors for LCOs found in legumes are classified in the lysin motif containing receptor-like kinase family (Liang et al. 2014). LysM receptors, found across all domains except Archaea (Gust et al. 2012), bind and respond to microbial associated molecular patterns (MAMPs) including chitin (Antolín-Llovera et al. 2012).

This similarity between plant receptor structure and activity across plant species suggests that the symbiotic pathway evolved from plant defense response pathways, and indeed, LCO - LysM binding has been found to be part of the plant immune response pathway (Rey et al. 2013). The NF receptor in the legume root hair epidermal plasma membrane has an extracellular LysM receptor-like kinase that binds with its cognate NF (Broghammer et al. 2012). This binding sets off a cascade of signaling events, including accumulation of cytokinins and calcium spiking, to initiate root hair curling, development of an infection thread and subsequent rhizobial infection (Oldroyd et al. 2011; Rose et al. 2012; van Zeijl et al. 2015). The subsequent mutual symbiotic infection occurs in plant-derived structures called nodules, where the bacteria fix atmospheric $\mathrm{N}$ in exchange for photosynthetically derived $\mathrm{C}$. Many thorough reviews detailing the primary research on plant LysM receptor evolution, mechanisms and function in both immunity and symbiosis have been published in the past 5 years (Antolín-Llovera et al. 2012; Gust et al. 2012; Limpens et al. 2015).

Due to the ubiquitous nature of plant LysM receptors, LCOs are important signal molecules in the rhizosphere and have also been shown to trigger plant growth enhancement effects in legumes and non-legumes alike. Many studies from the past two decades have observed increases in growth and germination of many different types of plants in response to application of rhizobial LCOs (Gautam et al. 2016; Marks et al. 2015; Prithiviraj et al. 2003; Souleimanov et al. 2002). However, few have sought to elucidate specific mechanisms or genetic pathways involved in the plant - microbe derived LCO signal molecule in order to understand the direct influence on improved plant nutrition. Candidates include the LysM receptor pathway, calcium signaling and influence on phytohormone pathways such as auxin.

LCOs can influence plant nutrition through alteration of root architecture. Changes in plant root architecture induced by bacteria in the rhizosphere have significant implications in plant health. Enhanced root surface and expansion of plant root systems increase the plant's ability to acquire nutrients. Application of LCO to M. truncatula was shown to increase lateral root branching via the same pathway required for symbiosis, the most notable component being the LysM nod factor receptors (Oláh et al. 2005). In the non-legume Arabidopsis thaliana (L.) grown in media containing the biologically relevant concentration of $10 \mathrm{nM}$ LCO from Bradyrhizobium japonicum, root tip numbers increased by $33 \%$, root length increased by $33 \%$, and root surface area increased $76 \%$ (Khan et al. 2011). Treatments containing various concentrations of chitin oligomers at similar concentrations did not result in any significant changes in root phenotype, indicating that the acylated moiety may be required for the growth response of Arabidopsis.

Further evidence of LCOs acting as generalized positive regulators of growth was demonstrated when seedlings of the $\mathrm{C} 4$ monocot Zea mays (maize) treated with $10 \mathrm{nM}$ LCO showed significant increases in lateral root 
lengths (Tanaka et al. 2015). Transcriptional expression analysis revealed changes in gene expression in response to LCO; genes involved in transcriptional regulation and secondary metabolism were upregulated and stress response genes were down-regulated. Four genes with strong positive responses to induction by LCO were further analyzed with promoter fusion reporters in transgenic maize roots. One of which, the gene encoding the calmodulin-binding protein $C a M B$, had a 3-fold increase in expression and primarily localized to the root epidermis, could have a role in affecting hormone ABA hormone signaling, and thus altering root growth and development.

Nop effectors of rhizobia type III secretion system (T3SS)

Plant hormone signaling directs both plant immunity (Pieterse et al. 2012) and plant growth and nutrition (Rubio et al. 2009). As such, shared components of these pathways result in a high level of crosstalk and trade-offs between defense and fitness (Denancé et al. 2013; Karasov et al. 2017; Takatsuji 2017). A critical component of rhizobia nodulation of its legume host is the requirement for the bacteria to suppress the plant's immune response, allowing for entry and infection to establish the symbiosis. LCO are shown to cause suppression of plant immunity; treatment with LCOs suppressed expression of the pathogenesis-related protein MtBGLU1 in M. truncatula (Mitra and Long 2004). In the non-legume Arabidopsis, LCOs suppressed FLS2 MAMP receptor based immunity, possibly through degradation of the FLS2 protein (Liang et al. 2013). Concomitant with this suppression is a positive growth response.

Other rhizobial molecules such as lipopolysaccharides (LPS) and exopolysaccharides (EPS) are implicated in the suppression of plant immunity to induce and maintain a successful infection (Aslam et al. 2008; Jones et al. 2008). While these carbohydrate signal molecules presumably interact at the plant cell membrane, an interesting mode of rhizobia-legume interaction occurs via rhizobia type III secretion systems (T3SS). T3SS are a mechanism to directly deliver effector proteins into the cell and are well studied in pathogenic bacteria (Ji and Dong 2015). Though not all rhizobia have T3SS, many genera have so far been described such as Sinorhizobium and Bradyrhizobium (Staehelin and Krishnan 2015). Nodulating outer proteins (Nops) are the effector proteins transported through T3SS and can be secreted from rhizobia in response to flavonoids (de Campos et al. 2011).

Nops are important in the recognition and formation of nodules independent of the presence of NFs. T3SS in B. elkani was found to be able to bypass the Nod factor receptor (NFR) and NF requirement to form nodules in soybean (Okazaki et al. 2013). The T3SS effector NopL from Rhizobium sp. strain NGR234 was found to prevent early nodule senescence in Phaseolus vulgaris (cv. Tendergreen) through interacting with the MAPK pathway (Zhang et al. 2011) In light of this, Nops are likely involved in suppressing the legume immune response. For further illustration, NopL is recognized as acting to block transcription of the PR proteins glucanases and chitinases regulated by the MAP kinase pathway (Bartsev et al. 2004), and has recently been found to be a substrate of plant defense-related MAP kinase involved in host defense suppression (Ge et al. 2016). Rhizobial products that suppress plant immunity are generally understood to be acting to allow sustained infection in the plant, but they may also be contributing to plant growth benefits by influencing these complex pathways and modulating trade-offs with fitness.

The substantial body of research in symbiotic factors in association with their legume host provides a strong model for the direction of studies that may be performed with these molecules to understand other PGPR-plant interactions to the same extent. Molecules produced by PGPRs in the rhizosphere range from simple amino acids to large polysaccharides and proteins, and as such, a wide variety of impacts on plant physiology are possible. Understanding the genetic basis of these relations may allow manipulation of the rhizospheres of crops to encourage and induce plant growth and nutrition.

Non-symbiotic bacterial molecules influencing plant growth and nutrition

Many rhizobacterial exo-metabolites also serve as MAMPs, eliciting a positive plant response through systemic defense priming (Wiesel et al. 2014), which will be discussed in the following section. Rhizobacterial chemicals can also directly influence plant nutrition and growth through alterations in plant physiological responses; the molecular pathways are not entirely resolved, and may overlap with known plant defense and symbiotic factors. Some studies have isolated a bacterial metabolite and observed a positive plant response, but the specific response pathway is unknown, while other 
work narrows down the PGPR organism and the transcriptional responses, without identifying the specific exo-metabolite inducer. It is clear that bacteria in the rhizosphere can influence plants directly through exudation of a multitude of chemical compounds such as secondary metabolites, and small signaling molecules.

\section{Phytohormones}

Both pathogenic and beneficial bacteria can produce phytohormones (Costacurta and Vanderleyden 1995; Jones and Dangl 2006; Spaepen 2015). In the rhizosphere, many PGPRs are known to promote plant growth, in part, due to the activity of substances that are also plant hormones, or that are structurally similar. These bacterially derived chemicals tend to be in the category of plant growth regulators such as auxin (IAA), gibberellic acid (GA) and ethylene (ET) (Gamalero and Glick 2011). Three strains of Bradyrhizobium japonicum were reported to produce significant levels of the hormones IAA, GA, zeatin, ethylene, and ABA (Boiero et al. 2007).

Auxin is a major regulator of plant growth, development and stress response (Liu et al. 2014). It is well known for its role in lateral root formation, and it is also a major player in nodule meristem elongation (Oldroyd et al. 2011). IAA production is widespread among both pathogens and PGPR in the soil and rhizosphere (Costacurta and Vanderleyden 1995). In pathogens, IAA production can be associated with their mode of virulence. For example, in $R$. solanacearum and Erwinia chrysanthemi, IAA synthesis occurs along with Type III secretion system expression, and A. tumefaciens transfers T-DNA encoding genes for the constitutive expression of IAA to produce undifferentiated tissue (tumors) in the plant (Spaepen and Vanderleyden 2011).

The PGPR B. amyloliquefaciens FZB42 produces IAA, which was found to be essential in its ability to promote plant growth (Idris et al. 2007). FZB42 grown with Lemna minor ST (duckweed) significantly increased fresh weight, while FZB42 mutants deficient in tryptophan (precursor to IAA) had no difference in fresh weight from controls. Earlier work by Kamilova et al. (2006) described the relatively high content of Ltryptophan in plant exudate from tomato, cucumber and radish, leading to the suggestion that auxin production by some PGPRs may be dependent on tryptophan substrate provided by the host. In that study, the researchers found that radish had the highest amount of tryptophan in its exudates, and that the PGPR P. fluorescens strain
WCS365 known to produce auxin in the presence of tryptophan provided the greatest amount of growth promotion in this plant (Kamilova et al. 2006).

Paenibacillus polymyxa strain BFKC01 is an example of a PGPR found to provide benefits spanning the major modes of improving plant nutrition, and enhancing biotic and abiotic resistance. In recent work by Zhou et al. (2016), BFKC01 produced measurable concentrations of IAA in culture (supplemented with tryptophan) and Arabidopsis inoculated with this strain had increased levels of IAA as measured by DR5:GUS reporter lines and gas chromatography. Arabidopsis Col0 inoculated with BFKC01 grown in Fe deficient medium produced significantly more lateral roots and higher plant biomass than control plants. The authors attribute the improved plant growth, in part, to the increased density of lateral roots which likely resulted from the presence of bacterially derived IAA.

\section{Bacterial volatiles}

Volatile organic compounds (VOC) are typically aromatic molecules produced by both plants and bacteria. In recent reviews, authors Chung et al. (2016) and Audrain et al. (2015) propose more specific terminology in reference to the suite of low molecular weight chemicals released by bacteria to reflect the presence of organic and inorganic compounds. The term 'bacterial volatile compound' (BVC) will be used in this review to align with this more recent viewpoint. BVCs are well documented to promote plant growth and induce plant defense responses (Farag et al. 2013). In a large scale screening study evaluating 42 rhizosphere bacteria and 4 different growth media, Blom et al. (2011) found that indole from Pseudomonas and Burkholderia species suppressed ethylene responses to the MAMP elicitor flg22. More recently, the same group described positive growth effects on Arabidopsis through the auxin root development pathway. When $10 \mathrm{nM}$ of indole was added to the growth media, A. thaliana seedlings lateral roots increased by $300 \%$. An intact polar auxin transport system was required, but it is not yet clear whether indole is the signal molecule or if it is used as a precursor for the IAA molecule causing the proliferation of lateral root primordia (Bailly et al. 2014).

Rhizosphere BVCs have also been shown to directly induce plant expression of nutrient ion transporters. The beneficial bacterium Bacillus subtilis GB03 enhances Arabidopsis iron accumulation via activation of the plant's 
own iron acquisition machinery (Zhang et al. 2009). Upon exposure to bacterial BVC, A. thaliana plants up-regulate the Fe-deficiency-induced transcription factor 1 (FIT1) that is necessary for GB03 BVC-induction of ferric reductase FRO2 and the iron transporter IRT1 expression (Zhang et al. 2009). The iron accumulation feature by this bacterium can also be triggered by direct application of GB03 bacterium, promoting iron acquisition in non-model plants. In cassava (Manihot esculenta), GB03 treatment of stem cuttings prior to planting promoted iron increase in the leaf by $400 \%$ (Freitas et al. 2015) and a $200 \%$ increase in root iron content in the field over a two year field trial (Freitas, unpublished), compared to untreated control. The increased iron uptake was accompanied not only by an increase in the photosynthetic rate but also a delay in leaf senescence. Interestingly, the PGPR P. polymyxa BFKC01 also increased the expression of AtFITI and IRT1 in inoculated Arabidopsis plants, though the bacterial elicitor was not investigated in this study, but it is intriguing to speculate to the role of BVC in this system (Zhou et al. 2016),

\section{Bacterial N-acyl homoserine lactones (AHLs)}

Many survival and infection activities of rhizosphere bacteria are under the control of the density-dependent communication system known as quorum sensing (QS). QS communication of bacteria in the rhizosphere most likely underlies a significant portion of intra- and inter-species interactions occurring in the rhizo-microbiome (Lowery et al. 2008). Both gram negative and gram positive bacteria participate in this mode of interaction, but with quite distinct differences in signal molecule structure and transcriptional response machinery. The most well studied QS system of Gram negative bacteria is composed of an extracellular signal molecule called an auto-inducer (AI), produced by an AI synthase, and a transcriptional response regulator protein to which the AI binds and upregulates expression of downstream operons involved in QS. Synthesis of the AI can be triggered initially by environmental conditions and as the population increases, the concentration of the signal builds in the environment, and a positive feedback loop can be enacted amongst the community of bacterial cells (Bassler and Miller 2013).

Numerous rhizosphere bacterial species are known to have QS control over functions related to their survival and activities in this environment (Pierson et al. 1998; Venturi and Fuqua 2013). QS regulation of bacterial activities can be tightly synchronized through AI structure and concentration, and through response regulator specificity; however, there is an abundance of evidence that QS is involved in inter-species crosstalk (Tashiro et al. 2013). Gram negative bacterial AI signals are Nacyl homoserine lactones (AHL), which consist of an invariant lactone ring and an acyl side-chain of varying lengths, saturation, and hydroxyl groups (Chernin 2011; Czajkowski and Jafra 2009). Rhizobia species seem to produce acyl chains with lengths ranging from C6 to $\mathrm{C} 18$, with a greater abundance of the long chain variants (Marketon et al. 2002; Teplitski et al. 2003). Rhizospheric Pseudomonas spp. AHL side chains can range from C6 to C12 (Ortíz-Castro et al. 2008).

Bacterial AHLs in the rhizosphere induce distinct responses in plants (Götz-Rösch et al. 2015; Schikora et al. 2016). Joseph and Phillips (2003) observed a significant increase of stomatal conductance and transpiration in Phaseolus vulgaris L. (bean) when $10 \mathrm{nM}$ AHL was applied to the roots (Joseph and Phillips 2003). In the legume $M$. truncatula, an increase in nodule number was found when S. meliloti-specific 3-oxo-C14-HL was applied to the roots (Veliz-Vallejos et al. 2014). Specific plant responses were demonstrated in the landmark work by Mathesius et al. (2003), who generated thorough protein expression data from M. truncatula exposed to AHL from its symbiont $S$. meliloti (3-oxo-C16:1-HL) and from the plant pathogen $P$. aeruginosa (3-oxo-C12$\mathrm{HL})$. The group found 154 proteins that were altered in accumulation, and identified 99 with homologs; two thirds of these proteins were the same for both AHLs, but $1 / 3$ of the proteins were altered between the AHL treatments. Roughly $23 \%$ of proteins with known homologies were related to plant defense, while $5 \%$ were involved in flavonoid synthesis and another $5 \%$ were related to hormone synthesis such as auxin.

Similar to the Mathesius et al. (2003) work, Miao et al. (2012) profiled the proteome of A. thaliana exposed to 3-oxo-C8-HL and found changes in accumulation of proteins related to defense response, protein biosynthesis, phyto-hormone response, metabolism and cytoskeleton remodeling (Miao et al. 2012). In alignment with these observations, many studies have described changes in root growth elicited by the application of AHL. von Rad et al. (2008) found transcriptional changes related to cell growth and growth hormones as well as root elongation in A. thaliana exposed to C6-HL (von Rad et al. 2008). Elongation of $A$. thaliana roots by 3-oxo-C6-HL and 3-oxo-C8-HL is proposed to be mediated through G-protein-coupled receptors GCR1 and GPA1 which are responsive to key plant hormones and 
play a role in root development (Liu et al. 2012). More recent work from this group has shown that the Arabidopsis growth and developmental protein AtCaM and the transcription factor AtMYB44 are key in the root elongation response to 3OC6-HSL (Zhao et al. 2014, 2016). Ortíz-Castro et al. (2008) found root architecture changes such as increased branching, lateral root hair primordia and root hair formation with the longer chain C10-HL (Ortíz-Castro et al. 2008). The application of 3-oxo-C10-HL induced adventitious root formation and auxin response gene expression in legume Vigna radiata (mung bean) seedlings (Bai et al. 2012).

More PGPR derived signaling molecules are sure to be identified as activating plant growth and nutrition pathways. An example of a potential inter-kingdom signaling molecule affecting both PGPR QS and plant growth are the cyclodipeptides (CDPs). Several different CDPs from $P$. aeruginosa were found to stimulate lateral growth, likely through acting as an auxin-like signal (Ortíz -Castro et al. 2011). Interestingly, the CDPs from $P$. aeruginosa may have multiple significant functions involved in plant beneficial interactions. Certain CDPs were found to act directly on the LasR AHL QS system to negatively control their own synthesis, which is important as larger concentrations of CDP are required to stimulate lateral root growth as compared to auxin (González et al. 2017). The same study used a bioinformatics approach to identify possible non ribosomal peptide synthases responsible for CDP production, and found highly homologous protein sequences associated with the production of the bacterial iron scavenging siderophore pyoverdine. The matching sequence encodes $\mathrm{PvdD}$, a synthase for pyoverdine and is under the regulatory control of LasR AHL QS regulation which is upregulated in iron starvation conditions (Stintzi et al. 1998). Intriguing recent research has re-iterated some known PGPR activities of pyoverdine, as well as illuminating more details of the plant responses to this siderophore.

\section{Siderophores}

As will be reviewed in the following sections, many bacterial products play a duel role in stimulating plant nutrition and in eliciting plant defense responses. Many of these products and mechanisms of PGPRs seem to influence the nexus of the plant pathways modulating the direction or 'choice' between the two, particularly during nutrient limiting conditions. One such example is the activity of the PGPR P. fluorescens C7R12 siderophore pyoverdine (Trapet et al. 2016). As is discussed in the publication of this study, PGPR siderophores can be assimilated by plants to scavenge for iron (Vansuyt et al. 2007) and also may be elicitors of plant resistance to pathogens as exogenous pyoverdine promoted ISR in bean and tomato (Meziane et al. 2005). Arabidopsis in iron-deficient conditions and in the presence of the uncomplexed iron siderophore pyoverdine experienced growth promotion at the expense of increased susceptibility to Botrytis cinerea. Furthermore, the researchers identified the HBII transcription factor as the node between plant growth and immunity (Trapet et al. 2016).

\section{PGPRs induce plant resistance}

Biotic stresses caused by pathogenic bacteria, fungus, virus and pests are significant limiting factors for crop yield and productivity. The limitations associated with the conventional breeding practices often lead to development of new techniques to enhance resistance against biotic stressors. Over the last several decades genetic engineering by transforming crop plants with resistance genes against various different biotic stress agents has led to some progress in increasing plant and crop resistance (Dangl et al. 2013). The ability of pests and pathogens to develop counter-resistance against both conventional breeding practices and genetic engineering approaches has led to major road blocks to boosting yields (Dively et al. 2016; Tabashnik et al. 2013). Utilization of synthetic chemicals to mitigate biotic stressors has turned out to be an effective strategy, but raises several other concerns such as shelf live and other non-target toxic residual effects to other benign organisms (Glick 2012). Harnessing benign microbes or "biologicals" for crop protection is an increasingly popular approach. However, the lack of reproducibility or mechanistic explanation for the biological controls can lead to reluctance in applying them at a large-scale for crop protection. Over the last several years, the impact of the plant-associated microbiome has led to an understanding that it plays a critical role in plant fitness and survival (Busby et al. 2017). The current knowledge of the beneficial microbiome and host interaction lacks key information pertaining to the signaling events and the components of innate immune responses that govern the interaction of plants with beneficial microbes.

Plants use a multitude of systemic signaling molecules, termed 'phytohormones', to regulate various stages of their 
development and to coordinate defense responses. These plant hormones are necessarily specific to the function they control, and much cross-talk exists between hormone pathways (Thaler et al. 2012). Phytohormones such as salicylic acid (SA), ethylene (ET), and jasmonic acid (JA) are tightly involved in plant defense response networks such as systemic acquired resistance (SAR), and induced systemic resistance (ISR) (Glazebrook 2005; Heil and Bostock 2002). SAR is induced by microbial associated molecular patterns (MAMPs). When the plant recognizes a microbial compound such as flagella or chitin through membrane bound pattern recognition receptors (PRRs), the plant marshals its first line of defense, MAMP triggered immunity (MTI). If this fails, the next line of defense is microbial effector triggered immunity (ETI) which includes programmed cell death. SAR occurs after PTI and/or ETI, and involves long-distance signaling via the plant phytohormone salicylic acid (SA) to upregulate PATHOGENISISRELATED (PR) genes encoding antimicrobial proteins $(\mathrm{Fu}$ and Dong 2013; Jones and Dangl 2006).

ISR is an inducible plant defense response triggered by non-pathogenic rhizobacteria, and it increases the plant's systemic resistance to subsequent pathogen challenge (Ongena and Jacques 2008). Unlike SAR, ISR has been found to act through a SA-independent pathway to confer systemic protection after exposure to beneficial microbes (Pieterse et al. 2014). Rather, ISR signaling pathways are thought to be based on the phytohormones ethylene (ET) and jasmonic ascid (JA) (Verhagen et al. 2004). ISR essentially allows the plant to more quickly activate its above-ground defenses against pathogens, which is known as 'priming' (Conrath et al. 2006) with a mobile signal in a root to shoot manner (Pieterse et al. 2014). These plant defense mechanisms are found plantwide; distinct MAMP responses having been demonstrated in A. thaliana roots where they seem to be ET dependent (Millet et al. 2010). The phenomenon of plant priming is widespread among known PGPRs and its distinct advantage is that fitness costs to the plant remain relatively low as compared to plant defense responses to triggering stress (Martinez-Medina et al. 2016).

Notably, several plant associated bacteria are reported to produce SA (Bakker et al. 2014). While these strains are confirmed to produce SA in culture, some doubt is cast as to whether the reports of elevated SA in the rhizospheres of inoculated plants are the result of an artifact in measurements. There seems to be no consensus as to whether SA from PGPR strains contributes to ISR induction. Through heterologous expression of SA production genes, it was demonstrated that the presence of bacteria-produced SA in some patho-systems indeed correlates to improved induction of ISR (Maurhofer et al. 1998). Others dispute as to whether measurements of PGPR-SA released into the rhizosphere may be plant derived or siderophores containing an SA-like derivative, and neither likely has an additional impact on the plants SA-dependent immune response (Bakker et al. 2014). Bacterial SA may not be playing a direct role, rather it is known to be a precursor to pyochelin (Pch) which, along with the phenazine pyocyanin, may be the true elicitor from $P$. aeruginosa $7 \mathrm{NSK} 2$ inducing ISR on tomato against $B$. cinerea (Audenaert et al. 2002).

Bacterial antibiotics can induce plant defense responses

Plant interactions with PGPR can be provoked via extracellular factors produced by the bacteria such as antibiotics. The most widely accepted definition of antibiotics is that they are chemically diverse, organic, low-molecular weight compounds produced by microorganisms that are deleterious to the growth or metabolic activities of other microorganisms (Thomashow and Weller 1996). Soil bacterial communities have been a resource of discoverable antibiotics for human use, especially during the "Golden Age" of antibiotic isolation spanning from the 1940's to the 1960's (Lewis 2013). A resurgent interest has emerged in isolating these soil and plant associated microbe products for curative use in agriculture in hopes of remedying microbial pathogencaused diseases (Mendes et al. 2011). Many antibiotics found to be produced by PGPRs act to benefit the plant indirectly through the traditional antibiotic context of killing plant pathogens (antagonism). In the following examples of this review, however, will be descriptions of direct plant responses to PGPR antibiotics.

One of the most studied PGPR antibiotics, 2,4diacetylphloroglucinol (DAPG), has been found in concentrations of $2.1 \mu \mathrm{g}$ per gram of soil associated with wheat roots (Bonsall et al. 1997) and is well-established to promote plant growth through its antibiotic activities toward plant fungal and bacterial pathogens (Weller et al. 2007). As with many other PGPR products, DAPG also may stimulate plant growth in some systems through increasing plant production of auxin and altering root architecture (Brazelton et al. 2008). DAPG is copiously produced by many rhizosphere strains of $P$. fluorescens, and is considered the primary attribute responsible for this family of PGPR to be so broadly effective (Weller et al. 
2012). Many strains of $P$. fluorescens also produce another class of antibiotics, phenazines, that have been recently implicated in inducing ISR in rice challenged with Magnaporthe oryzae (Ma et al. 2016).

Early on in the investigations of DAPG plant growth promotional activity, this antibiotic was discovered to also act as an elicitor of ISR. Iavicoli et al. (2003), using the pathosystem of Arabidopsis, the PGPR Pseudomonas fluorescens CHA0r and the oomycete Peronospora parasitica, reported that CHA0r inoculation reduced sporulation and colonization of the leaf parasite through a DAPG-dependent induction of ISR. Direct applications of DAPG $(10-100 \mu \mathrm{M})$ mimicked the ISR protective qualities of CHA0r and DAPG-production mutants of the PGPR were unable to induce the ISR response in Arabidopsis. Further investigation using Arabidopsis defense pathway mutants revealed the requirement for NPR1-1, JAR1 and EIR1 for the DAPG-induced ISR response. Intriguingly, the investigators found through other mutant, gene expression and phytohormone assays that SA and JA are not likely to be involved directly in the DAPG-ISR pathway, noting that the mutation in EIR1 may act independently of the ET pathway and that it would be difficult to assign a definitive pathway in this system (Iavicoli et al. 2003). Though Iavicoli et al. 2003 found no ISR protection using CHA0r and the pathogens Botrytis cinerea and P. syringae pv. tomato DC3000, other strains of $P$. fluorescens such as WCS417r have been found to elicit ISR protection from Pst DC3000 and Fusarium oxysporum f. sp. raphanin (Pieterse et al. 1998).

Another powerful class of antibiotics isolated from rhizobacteria is the lipopeptides (LP), which can be linear or cyclic oligopeptides of various sizes and having a lipid tail of various lengths. The majority are cyclic lipopeptides (cLPs); defined as a heptapeptide interlinked with a $\beta$-hydroxy fatty acid to form a cyclic lactone ring structure (Ongena and Jacques 2008). cLPs known to date have been isolated primarily from Pseudomonas and Bacillus species, each having their own assortment of unique cLP configurations (Raaijmakers et al. 2010). The wellstudied cLPs from Bacillus spp. include surfactin, iturin and fengycin. Surfactin is produced in significant quantities by Bacillus spp. (Nihorimbere et al. 2012), and is considered one of the most potent natural surfactants known, acting through disrupting biological membranes (Carrillo et al. 2003). Due to their amphiphilic structures, cLPs are able to intercalate into lipid bilayers, forming pores and disrupting the membrane structure depending on the concentration of the cLP (Ongena and Jacques 2008).

Cyclic lipopeptide bacterial antibiotics, particularly surfactin, are copiously produced by Bacillus spp. (Ongena and Jacques 2008). The Bacillus group is well represented in the rhizosphere and is estimated to make up $95 \%$ of the gram positive bacteria found there (Prashar et al. 2013). Surfactin serves many roles in the rhizosphere, such as antibiosis, and has also been found to be required for attachment to the plant root (Bais et al. 2004; Ongena and Jacques 2008). Importantly, surfactin is able to stimulate direct plant responses at the root in the form of induced systemic resistance (ISR) (Ongena et al. 2007). Known bacterial elicitors of ISR are MAMPs such as flagella and lipo-polysaccharides (LPS) (De Vleesschauwer and Höfte 2009), but more recently, other bacterially derived substances such as cLPs have been found to induce ISR. Not only do a broad range of plants have an ISR response to surfactin, but many members of B. subtilis and B. amyloliquefaciens groups produce sufficient surfactin to provide disease protection via ISR (Cawoy et al. 2014).

In experiments with bean and tomato plants Ongena et al. (2007) found that inoculation with the surfactinproducing B. subtilis 499 increased disease suppression by $33 \%$ against the challenging pathogen Botrytis cinerea. Application of purified surfactin increased disease control by $28 \%$. The stimulation of ISR was demonstrated by using surfactin overproducing strains of Bacillus spp. and surveying a key ISR indicator, the Lipoxygenase (LOX) enzyme. Three-fold increases in LOX activity were observed in Botrytis-challenged tomato plants inoculated with the Bacillus spp. surfactin overproducer (Ongena et al. 2007). ISR defense responses were revealed in a study on Lolium perenne (perennial ryegrass) challenged with Magnaporthe oryzae. When inoculated with surfactin and with live cells of B. amyloliquefaciens FZB42-AK3, ryegrass presented with enhanced accumulation of hydrogen peroxide, higher peroxidase activity, deposition of callose and the hypersensitive response (HR) response; all indicators of ISR (Rahman et al. 2015).

Also of note, $B$. subtilis surfactin production is under the control of the QS regulon comQXPA, wherein the signal molecule secreted from the cell is a short, ribosomally synthesized, peptide called ComX (Dogsa et al. 2014). The work of Oslizlo et al. (2015) evaluated the diversity of QS 'pherotypes' (correlated to polymorphisms in the comQXPA QS system) and the relationship 
to plant beneficial activities (primarily surfactin production) in B. subtilis isolated from the rhizoplane of tomato. The comQXPA QS and other QS systems in Grampositive bacteria have unique and diverse extracellular signaling molecules.

Quorum sensing signals induce plant defense responses

Plants have been shown to up-regulate defense and immune response systems when treated with AHLs, the Gram-negative QS signal molecule. Arabidopsis had greater resistance to $P$. syringae pv tomato (Pst) when inoculated with 3-oxo-C14-HL-producing S. meliloti (Zarkani et al. 2013). Direct application of AHLs and inoculation of tomato with AHL-producing bacteria S. liquefaciens MG1 and P. putida IsoF increased the resistance to the pathogen A. alternata, increased SA levels in the plant and upregulated PR1, indicating that the AHL induced ISR (Schuhegger et al. 2006). Schikora et al. (2011) also found increased PR1 expression in A. thaliana challenged with the pathogen-associated molecular pattern (PAMP), flg22 when roots were treated with oxo-C14-HL. Systemic resistance was also induced by the AHL when A. thaliana was challenged with the fungal pathogen Golovinomyces orontii and the bacterial pathogen P. syringae pv tomato DC3000 (Schikora et al. 2011). Further evidence of AHL defense priming was revealed when oxo-C14-HL caused hallmark defense responses such as increased callose deposition, cell wall lignification and accumulation of phenolic substances, as well as increased SA, leading to stomatal closure in A. thaliana when challenged with $P$. syringae (Schenk et al. 2014).

The "universal' QS signal molecule, AI-2 is a cyclic structure containing boron encoded by the luxS gene (Chen et al. 2002). It is found in a wide variety of both Gram-positive and Gram-negative bacteria. The broad distribution of AI-2 implicates it as being involved in inter-kingdom signaling (Schauder et al. 2001), and this suggests that it could have an impact on plant growth or immunity. AI-2 responses have been observed in $S$. meliloti which doesn't produce AI-2 signals (Pereira et al. 2008) and certain strains of B. subtilis found in dairies are known to have intact luxS AI-2 QS systems (Duanis-Assaf et al. 2015); both bacteria species are represented in the rhizosphere. Recently, through the use of AI-2 receptor LuxP/LsrB reporter strains, mammalian epithelial cells were found to produce AI-2 'mimic' molecules in response to co-culture with bacteria. The authors proposed that the utility of the AI-2 signal could be in establishing inter-kingdom symbiosis (Ismail et al. 2016). However, unlike the Gram-negative AHL QS signal molecule, no work to date has investigated the direct plant responses to other QS signals such as AI-2 or the comQXPA QS system signal ComX.

Rhizosphere BVCs induce plant systemic priming defenses

The release of BVCs in the rhizosphere stimulate diverse responses in plants, enhancing both nutrition/biomass and defense (Chung et al. 2016). Seminal work by Ryu et al. (2004) established the role of BVC in the induction of plant ISR through the implementation of elegant 'split-plate' studies of Arabidopsis seedlings challenged with Erwinia carotovora subsp. carotovora SCC1. The PGPR bacteria were grown in the same plate on the opposite side of the barrier (Ryu et al. 2004). The ISReliciting compounds 2, 3-butanediol and 3-hydroxy-2butanone (collectively termed 'acetoin') were identified from B. subtilis GB03 and B. amyloliquefaciens IN937a, and the ISR protection was found to act primarily through the ET dependent pathway. Subsequent studies by Ryu and other groups have further identified specific BVCs and other pathosystems in which they and their PGPR producer effectively promote ISR.

For example, acetoin was also the active BVC from B. subtilis FB17 in the Arabidopsis - Pseudomonas syringae pv. tomato DC3000 system; this ISR was found to be dependent on SA and ET (Rudrappa et al. 2010). Other examples are: 2-pentanol from Bacillus amyloliquefaciens strain IN937a promotes effective ISR in pepper against Xanthomonas axonopodis pv. vesicatoria in an SA and JA dependent pathway (Choi et al. 2014), and the PGPR Bacillus cereus C1L produces dimethyl disulfide (DMDS) which induces ISR in tobacco and corn challenged with fungal pathogens (Huang et al. 2012).

Zamioudis et al. 2015 has demonstrated that volatiles from the PGPR $P$. simiae WCS417 induced ISR in Arabidopsis in a MYB72-dependent manner. Moreover, the BVCs from WCS417 upregulated MYB72 expression concomitant with iron starvation response genes including FIT1 (Zamioudis et al. 2015). The BVCinduced upregulation of MYB72 was independent of iron availability and the ability of the plant to acquire Fe was enhanced through upregulation of Fe-deficiency genes. The jack-of-all-trades PGPR P. polymyxa strain BFKC01, which was noted in the above section for its 
ability to improve plant nutrition through IAA production, was also found to induce ISR in Arabidopsis through increasing the transcription of MYB72. As might be expected, this PGPR also improved Fe uptake through upregulating the $\mathrm{Fe}$ deficiency transcription factor FIT1 (Zhou et al. 2016). Though an elicitor was not investigated in this work, other strains of P. polymyxa such as E681 have been found to induce ISR in Arabidopsis through production of a multitude of BVCs, including methanethiol, isoprene, acetic acidbutyl ester, acetoin, and in this case, the unique low molecular weight compound tridecane (Lee et al. 2012). Other recent work invokes the tight connection between microbial-mediated plant defense hormone pathways and the plant nutrient deficiency sensing networks such as phosphate (Castrillo et al. 2017), and highlights the cross-connectivity of PGPR-induced plant responses to multifaceted challenges.

Diverse PGPR molecules elicit plant defense

A selection of various proteins and small molecules from PGPRs have been found that seem to act by promoting plant defense pathways, but due to space and in some cases, a dearth of research, will only be mentioned in brief. Several bacterial proteins found to be salient in PGPR activities will not be comprehensively assessed in this review. Several uncharacterized proteins, one from Bacillus amyloliquefaciens NC6 (protein 'PeBA1') and the other from Brevibacillus laterosporus strain A60 (protein 'PeBL1') activate ISR responses in tobacco against TMV and $P$. syringae pv. tabaci, and $B$. cinerea (Wang et al. 2015, 2016), but further investigations have not yet been published. The small molecule phenylacetic acid (PAA) is classified as an antimicrobial, but PAA isolated from Azospirillum brasilense was found to be similar to auxin (Somers et al. 2005). More recently, PAA from Bacillus fortis IAGS162 was shown to be the elicitor of ISR in tomato against $F$. oxysporum f.sp. lycopersici (Akram et al. 2016). Through metabolomics techniques, the PGPR Pseudomonas aeruginosa PM12 was found to promote ISR in tomato challenged with F. oxysporum via 3-hydroxy-5-methoxy benzene methanol (HMB). A soil drench of $1.0 \mathrm{mM}$ and $10.0 \mathrm{mM} \mathrm{HMB}$ significantly reduced the disease index.

HMB (Fatima and Anjum 2017). The bacteriocin peptide Thuricin 17 (Th17) from the PGPR Bacillus thuringiensis strain NEB17, has long been known to have antimicrobial activities (Gray et al. 2006), but recent proteomic analysis of salt-stress Arabidopsis suggests that it may alleviate the deleterious effect of the abiotic stress on photosystems I and II through upregulation of chloroplast proteins (Subramanian et al. 2016).

PGPR also function to elicit plant abiotic defense responses

Abiotic challenges to plants are particularly pernicious, as plants must manifest their responses by utilizing the limited genetic plasticity gained through evolution. Plants may be exposed to transient or long term environmental stresses such as drought, flooding, extreme heat, freezing, or excessive salt (Mickelbart et al. 2015). Similar to plant biotic resistance, plant abiotic resistance relies on genetic regulatory mechanisms induced by changes in key phytohormone pathways that intersect in a complex manner (Verma et al. 2016). Abscisic acid (ABA) is most often associated with the plant's abiotic stress response strategy, especially in an antagonistic continuum with cytokinin (Yang et al. 2009). Classical defense response pathway genes such as the widespread plant transcription factor WRKY and the ABA responsive MYB factor are often used as signifiers of an abiotic resistance response, most commonly drought and salt stress challenges (Agarwal et al. 2011; Yanhui et al. 2006).

Many studies have observed increased ABA accumulation in PGPR-inoculated plants under various abiotic stress conditions. Bacillus licheniformis SA03-treated Chrysanthemum morifolium in saline-alkaline conditions had nearly double the level of ABA in leaves than the control as detected by ELISA (Zhou et al. 2017). Plants inoculated with SA03 and exposed to saline-alkaline stress conditions showed fewer symptoms and had higher fresh and dry shoot weights, whereas inoculated plants treated with the ABA inhibitor FLU exhibited no tolerance to the stress. The PGPR Bacillus aryabhattai strain SRB02 enhanced levels of ABA in soybean under control and heat stress (again, nearly double that of controls) and the inoculated plants were observed to have ABAmediated stomatal closure during heat stress (Park et al. 2017). Inoculation of Vitis vinifera with Bacillus licheniformis Rt4M10 increased ABA concentrations in leaves (fresh weight) by 76-fold and inoculation with Pseudomonas fluorescens Rt6M10 resulted in ABA increasing by 40 -fold; rates of water loss were also reduced in correlation with the increases of ABA in PGPRinoculated V. vinifera (Salomon et al. 2014) 
The products of PGPRs which specifically induce abiotic resistance or tolerance are not as well described in the literature as those known to be involved in defense priming, but likely overlap with those found to promote plant nutrition and biotic resistance. Indeed, reported examples of abiotic resistance elicitors include PGPR products such as ACC deaminase (Glick et al. 2007), phytohormones such as IAA (Marulanda et al. 2009), signal molecules such as LCOs (Subramanian et al. 2016) and AHLs (Ding et al. 2016), and BVCs (Liu and Zhang 2015). Promising recent research into the role of PGPR BVCs on Arabidopsis salinity tolerance has shown that the Paraburkholderia phytofirmans PsJN BVCs 2-undecanone, 7-hexanol, 3methylbutanol and dimethyl disulfide (DMDS) stimulated positive plant growth under both normal and saline-stress conditions (Ledger et al. 2016).
The PGPR Dietzia natronolimnaea strain STR1 confers salt tolerance to wheat (Triticum aestivum L.). STR1-inoculated plants had increased expression of the SOS4 pyridoxal kinase, which controls $\mathrm{N}^{+}$and $\mathrm{K}^{+}$ balance through adjusting ion transporter activity, and modulated TaMYB and TaWRKY transcriptions factor expression. However, this strain does not have commonly known plant beneficial traits such as IAA production and ACC deaminase activity (Bharti et al. 2016). D. natronolimnaea STR1 is known in other environmental contexts to produce high levels of carotenoids, which could be an intriguing new PGPR metabolite to investigate (Gharibzahedi et al. 2014).

An example of a bacterially-mediated sodium tolerance mechanism is from work that specifically investigated the Arabidopsis HKT1 gene encoding a high affinity potassium transporter involved in $\mathrm{Na}^{+}$import into the plant root.
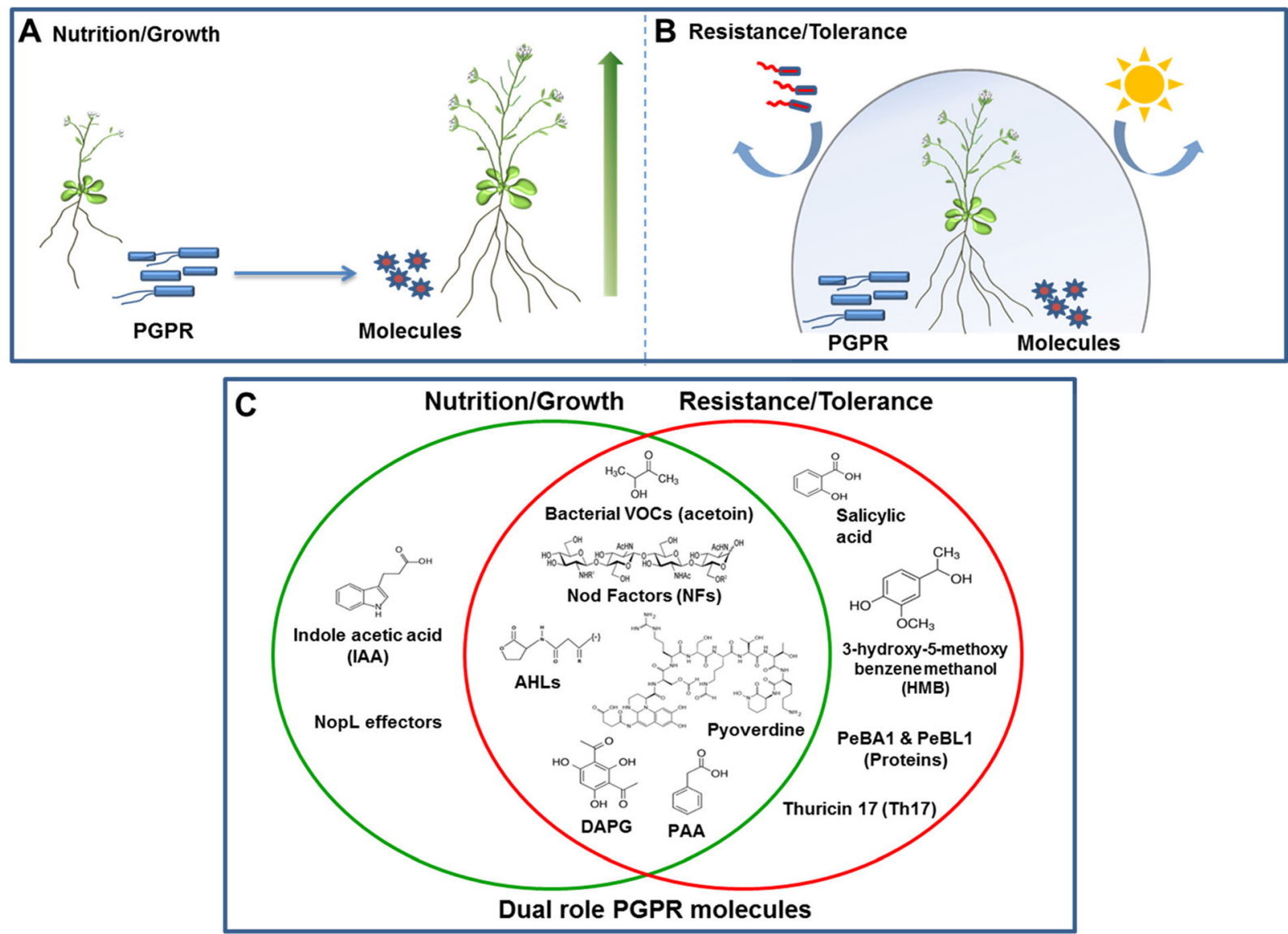

Fig. 1 Plant benefits conferred by PGPR and their products can be viewed in two broad categories. A. PGPRs and associated molecules improve plant nutrition and growth. B. PGPR molecules can also act to increase plant resistance and tolerance to biotic and abiotic challenges. C. Many PGPR molecules can positively affect both plant growth and plant resistance through overlapping mechanisms 
Treatment with the PGPR B. subtilis GB03 resulted in an orchestrated down-regulation in the roots and upregulation in the shoots of HKT1. Plants in these treatments had lower levels of sodium uptake overall. This response is particularly intriguing considering that $H K T 1$ overexpression in Arabidopsis does not increase salt tolerance. Also, salt tolerance in $h t k l$ mutants could not be restored by B. subtilis GB03 treatment (Zhang et al. 2008). More in-depth investigations will be helpful in determining the additional factors and mechanisms that the PGPR is implementing in conferring salt tolerance to plants.

Furthermore, drought tolerance in plants is associated with tolerance to vessel clogging or destruction-related diseases such as Fusarium oxysporum in an abiotic-related manner (Dowd et al. 2004). In cotton, an up-regulation of P5CS gene and proline abundance in stems are enhanced in PGPR-treated plants compared to control plants both inoculated with Rhizoctonia solani (Medeiros et al. 2011). The specific role of such induced drought-related tolerance on the disease control is yet to be determined.

This is an enticing glimpse into the potential direct genetic and transcriptional mechanisms of PGPR on the plant. However, at this juncture, the field is still somewhat intractable due to the complexity of plant hormone signaling pathways and their control over multiple plant growth, development and defense regimes. Despite the challenging nature of these interactions, it is clearly worthwhile to consider the promising examples of PGPR amelioration of abiotic challenges to plants. Unraveling the inter-relationships between PGPR and plant genetic mechanisms is imperative considering the urgent need to address these issues in our agroecosystems.

\section{Conclusion}

Clearly, PGPR are influencing plant growth and nutrition in very specific ways involving bacterial components inducing plant responses. Molecules from PGPRs can affect the plant in complex and overlapping mechanisms; sometimes influencing both plant growth and nutrition and resistance concomitantly. In other instances, the same PGPR product will promote plant health in only one specific way dependent on the type of plant host as well as the biotic and abiotic challenges present (see Fig. 1).

Many PGPR studies are focused on screening and identifying the species and strains of PGPRs associated with specific plant hosts (Finkel et al. 2017). At this juncture, the field is primed to move beyond correlation, and make great strides in understanding plant beneficial mechanisms. PGPR research should begin to focus on understanding not only the genetic factors, but also the context of the genetic mechanisms underlying plant beneficial microbial activities. The ability to 'engineer' the rhizosphere (Dessaux et al. 2016) will be more effective as we move away from the current paradigm of species-based consortia and microbiome cataloguing (Maymon et al. 2015; Schlaeppi and Bulgarelli 2015). The functions conferred by the changes in plant expression induced by the microbiome as a whole may prove to be more relevant than the specific microbe species enacting those changes, and the mechanisms by which the microbes act could be key in future applied PGPR development. With this in mind, concomitant explorations of microbial genetic manipulation of the plant, and chemical genomics approaches (Stokes and McCourt 2014) to evaluate key microbial molecular components inducing plant beneficial responses could allow for significant progress in understanding and implementing PGPR in the field. By identifying and elucidating the specific mechanisms of microbial-plant beneficial activity, safer, more effective and sustainable PGPR applications may be developed for agricultural and horticultural management practices.

Acknowledgments Authors thank the two anonymous reviewers for their valuable comments that helped to improve the manuscript. A.R acknowledges the support from Delaware Environmental Institute (DENIN) for DENIN Environmental Fellowship.

\section{References}

Asterisks $(*)$ denote the work is a review article.

*Agarwal P, Reddy MP, Chikara J (2011) WRKY: its structure, evolutionary relationship, DNA-binding selectivity, role in stress tolerance and development of plants. Mol Biol Rep 38:3883-3896

Akram W, Anjum T, Ali B (2016) Phenylacetic acid is ISR determinant produced by Bacillus fortis IAGS162, which involves extensive re-modulation in metabolomics of tomato to protect against Fusarium wilt. Front Plant Sci 7:498

*Alori ET, Glick BR, Babalola OO (2017) Microbial phosphorus solubilization and its potential for use in sustainable agriculture. Front Microbiol 8:971 
*Antolín-Llovera M, Ried MK, Binder A, Parniske M (2012) Receptor kinase signaling pathways in plant-microbe interactions. Annu Rev Phytopathol 50:451-473

Aslam SN, Newman M-A, Erbs G, Morrissey KL, Chinchilla D, Boller T, Jensen TT, De Castro C, Ierano T, Molinaro A, Jackson RW, Knight MR, Cooper RM (2008) Bacterial polysaccharides suppress induced innate immunity by calcium chelation. Curr Biol CB 18:1078-1083

Audenaert K, Pattery T, Cornelis P, Höfte M (2002) Induction of systemic resistance to Botrytis cinerea in tomato by Pseudomonas aeruginosa 7NSK2: role of salicylic acid, pyochelin, and pyocyanin. Mol Plant-Microbe Interact MPMI 15:1147-1156

*Audrain B, Farag MA, Ryu C-M, Ghigo J-M (2015) Role of bacterial volatile compounds in bacterial biology. FEMS Microbiol Rev 39:222-233

Bai X, Todd CD, Desikan R, Yang Y, Hu X (2012) N-3-oxodecanoyl-L-homoserine-lactone activates auxin-induced adventitious root formation via hydrogen peroxide- and nitric oxide-dependent cyclic GMP signaling in mung bean. Plant Physiol 158:725-736

Bailly A, Groenhagen U, Schulz S, Geisler M, Eberl L, Weisskopf L (2014) The inter-kingdom volatile signal indole promotes root development by interfering with auxin signaling. Plant $\mathrm{J}$ Cell Mol Biol 80:758-771

Bais HP, Fall R, Vivanco JM (2004) Biocontrol of Bacillus subtilis against infection of Arabidopsis roots by Pseudomonas syringae is facilitated by biofilm formation and surfactin production. Plant Physiol 134:307-319

*Bakker, PAHM, Ran L, Mercado-Blanco J (2014) Rhizobacterial salicylate production provokes headaches! Plant Soil 382:1. https://doi.org/10.1007/s11104-014-2102-0

Bartsev AV, Deakin WJ, Boukli NM, McAlvin CB, Stacey G, Malnoë P, Broughton WJ, Staehelin C (2004) NopL, an effector protein of Rhizobium sp. NGR234, thwarts activation of plant defense reactions. Plant Physiol 134:871-879

*Bassler BL, Miller MB (2013) Quorum sensing. In: Rosenberg E., DeLong E.F., Lory S., Stackebrandt E., and Thompson F. (eds) The prokaryotes. Springer Berlin Heidelberg, p 495-509

*Bektas Y, Eulgem T (2014) Synthetic plant defense elicitors. Front Plant Sci 5:804

Bharti N, Pandey SS, Barnawal D, Patel VK, Kalra A (2016) Plant growth promoting rhizobacteria Dietzia natronolimnaea modulates the expression of stress responsive genes providing protection of wheat from salinity stress. Sci Rep 6:34768

Blom D, Fabbri C, Connor EC, Schiestl FP, Klauser DR, Boller T, Eberl L, Weisskopf L (2011) Production of plant growth modulating volatiles is widespread among rhizosphere bacteria and strongly depends on culture conditions. Environ Microbiol 13:3047-3058

Boiero L, Perrig D, Masciarelli O, Penna C, Cassán F, Luna V (2007) Phytohormone production by three strains of Bradyrhizobium japonicum and possible physiological and technological implications. Appl Microbiol Biotechnol 74: 874-880

Bonsall RF, Weller DM, Thomashow LS (1997) Quantification of 2,4-diacetylphloroglucinol produced by fluorescent Pseudomonas spp. in vitro and in the rhizosphere of wheat. Appl Environ Microbiol 63:951-955
Brazelton JN, Pfeufer EE, Sweat TA, Gardener BBM, Coenen C (2008) 2,4-diacetylphloroglucinol alters plant root development. Mol Plant-Microbe Interact MPMI 21:1349-1358

Broghammer A, Krusell L, Blaise M, Sauer J, Sullivan JT, Maolanon N, Vinther M, Lorentzen A, Madsen EB, Jensen KJ, Roepstorff P, Thirup S, Ronson CW, Thygesen MB, Stougaard J (2012) Legume receptors perceive the rhizobial lipochitin oligosaccharide signal molecules by direct binding. Proc Natl Acad Sci U S A 109:13859-13864

*Busby PE, Soman C, Wagner MR, Friesen ML, Kremer J, Bennett A, Morsy M, Eisen JA, Leach JE, Dangl JL (2017) Research priorities for harnessing plant microbiomes in sustainable agriculture. PLoS Biol 15:e2001793. https://doi. org/10.1371/journal.pbio.2001793

de Campos SB, Deakin WJ, Broughton WJ, Passaglia LMP (2011) Roles of flavonoids and the transcriptional regulator TtsI in the activation of the type III secretion system of Bradyrhizobium elkanii SEMIA587. Microbiol Read Engl 157:627-635

*Carrillo C, Teruel JA, Aranda FJ, Ortíz A (2003) Molecular mechanism of membrane permeabilization by the peptide antibiotic surfactin. Biochim Biophys Acta 1611:91-97

Castrillo G, Teixeira PJPL, Paredes SH, Law TF, de Lorenzo L, Feltcher ME, Finkel OM, Breakfield NW, Mieczkowski P, Jones CD, Paz-Ares J, Dangl JL (2017) Root microbiota drive direct integration of phosphate stress and immunity. Nature 543:513-518

Cawoy H, Mariutto M, Henry G, Fisher C, Vasilyeva N, Thonart P, Dommes J, Ongena M (2014) Plant defense stimulation by natural isolates of Bacillus depends on efficient surfactin production. Mol Plant-Microbe Interact MPMI 27:87-100

Chen X, Schauder S, Potier N, Van Dorsselaer A, Pelczer I, Bassler BL, Hughson FM (2002) Structural identification of a bacterial quorum-sensing signal containing boron. Nature 415:545-549

*Chernin LS (2011) Quorum-sensing signals as mediators of PGPRs' beneficial traits. In: Maheshwari D.K. (ed) Bacteria in agrobiology: plant nutrient management. Springer Berlin Heidelberg, p 209-236

*Chin-A-Woeng TFC, Bloemberg GV, Lugtenberg BJJ (2003) Phenazines and their role in biocontrol by Pseudomonas bacteria. New Phytol 157:503-523

Choi HK, Song GC, Yi H-S, Ryu C-M (2014) Field evaluation of the bacterial volatile derivative 3-pentanol in priming for induced resistance in pepper. J Chem Ecol 40:882-892

*Chung J, Song GC, Ryu C-M (2016) Sweet scents from good bacteria: case studies on bacterial volatile compounds for plant growth and immunity. Plant Mol Biol 90:677-687

*Conrath U, Beckers GJM, Flors V, García-Agustín P, Jakab G, Mauch F, Newman M-A, Pieterse CMJ, Poinssot B, Pozo MJ, Pugin A, Schaffrath U, Ton J, Wendehenne D, Zimmerli L, Mauch-Mani B (2006) Priming: getting ready for battle. Mol Plant-Microbe Interact 19:1062-1071

*Costacurta A, Vanderleyden J (1995) Synthesis of phytohormones by plant-associated bacteria. Crit Rev Microbiol 21:1-18

*Czajkowski R, Jafra S (2009) Quenching of acyl-homoserine lactone-dependent quorum sensing by enzymatic disruption of signal molecules. Acta Biochim Pol 56:1-16 
* Dangl JL, Horvath DM, Staskawicz BJ (2013) Pivoting the plant immune system from dissection to deployment. Science 341: $746-751$

*De Vleesschauwer D, Höfte M (2009) Chapter 6 Rhizobacteriainduced systemic resistance. Adv Bot Res 51:223-281. https://doi.org/10.1016/S0065-2296(09)51006-3

*Denancé N, Sánchez-Vallet A, Goffner D, Molina A (2013) Disease resistance or growth: the role of plant hormones in balancing immune responses and fitness costs. Front Plant Sci 4:155

*Dessaux Y, Grandclément C, Faure D (2016) Engineering the rhizosphere. Trends Plant Sci 21: 266-278

Ding L, Cao J, Duan Y, Li J, Yang Y, Yang G, Zhou Y (2016) Proteomic and physiological responses of Arabidopsis thaliana exposed to salinity stress and $\mathrm{N}$-acyl-homoserine lactone. Physiol Plant 158:414-434

Dively GP, Venugopal PD, Finkenbinder C (2016) Field-evolved resistance in corn earworm to cry proteins expressed by transgenic sweet corn. PLoS One 11:e0169115. https://doi. org/10.1371/journal.pone.0169115

Dogsa I, Choudhary KS, Marsetic Z, Hudaiberdiev S, Vera R, Pongor S, Mandic-Mulec I (2014) ComQXPA quorum sensing systems may not be unique to Bacillus subtilis: a census in prokaryotic genomes. PLoS One 9:e96122. https://doi. org/10.1371/journal.pone.0096122

Dowd C, Wilson IW, McFadden H (2004) Gene expression profile changes in cotton root and hypocotyl tissues in response to infection with Fusarium oxysporum $f . s p$. vasinfectum. Mol Plant-Microbe Interact MPMI 17:654-667

Duanis-Assaf D, Steinberg D, Chai Y, Shemesh M (2015) The LuxS based quorum sensing governs lactose induced biofilm formation by Bacillus subtilis. Front Microbiol 6:1517

Farag MA, Zhang H, Ryu C-M (2013) Dynamic chemical communication between plants and bacteria through airborne signals: induced resistance by bacterial volatiles. J Chem Ecol 39:1007-1018

Fatima S, Anjum T (2017) Identification of a potential ISR determinant from Pseudomonas aeruginosa PM12 against Fusarium wilt in tomato. Front Plant Sci 8:848

*Finkel OM, Castrillo G, Herrera Paredes S, Salas González I, Dangl JL (2017) Understanding and exploiting plant beneficial microbes. Curr Opin Plant Biol 38: 155-163

Freitas MA, Medeiros FHV, Carvalho SP, Guilherme LRG, Teixeira WD, Zhang H, Paré PW (2015) Augmenting iron accumulation in cassava by the beneficial soil bacterium Bacillus subtilis (GBO3). Front Plant Sci 6:596

*Friesen ML, Porter SS, Stark SC, Wettberg EJ von, Sachs JL, Martinez-Romero E (2011) Microbially mediated plant functional traits. Annu Rev Ecol Evol Syst 42: 23-46

*Fu ZQ, Dong X (2013) Systemic acquired resistance: turning local infection into global defense. Annu Rev Plant Biol 64: 839-863

*Fujita M, Fujita Y, Noutoshi Y, Takahashi F, Narusaka Y, Yamaguchi-Shinozaki K, Shinozaki K (2006) Crosstalk between abiotic and biotic stress responses: a current view from the points of convergence in the stress signaling networks. Curr Opin Plant Biol 9: 436-442

*Gamalero E, Glick BR (2011) Mechanisms used by plant growth-promoting bacteria. In: Maheshwari D.K. (ed) Bacteria in agrobiology: plant nutrient management. Springer Berlin Heidelberg, p 17-46
*Gauri SS, Mandal SM, Pati BR (2012) Impact of Azotobacter exopolysaccharides on sustainable agriculture. Appl Microbiol Biotechnol 95: 331-338

Gautam K, Schwinghamer TD, Smith DL (2016) The response of soybean to nod factors and a bacteriocin. Plant Signal Behav 11:e1241934. https://doi. org/10.1080/15592324.2016.1241934

Ge Y-Y, Xiang Q-W, Wagner C, Zhang D, Xie Z-P, Staehelin C (2016) The type 3 effector NopL of Sinorhizobium sp. strain NGR234 is a mitogen-activated protein kinase substrate. J Exp Bot 67:2483-2494

Gharibzahedi SMT, Razavi SH, Mousavi M (2014) Feeding strategies for the improved biosynthesis of canthaxanthin from enzymatic hydrolyzed molasses in the fed-batch fermentation of Dietzia natronolimnaea HS-1. Bioresour Technol 154:51-58

*Glazebrook J. (2005) Contrasting mechanisms of defense against biotrophic and necrotrophic pathogens. Annu Rev Phytopathol 43: 205-227

*Glick BR (2012) Plant growth-promoting bacteria: mechanisms and applications. Scientifica 2012, Article ID 963401, 15 pages, 2012. https://doi.org/10.6064/2012/963401

*Glick BR. (2014) Bacteria with ACC deaminase can promote plant growth and help to feed the world. Microbiol Res 169: 30-39

*Glick BR, Todorovic B, Czarny J, Cheng Z, Duan J, McConkey B (2007) Promotion of plant growth by bacterial ACC deaminase. Crit Rev Plant Sci 26: 227-242

González O, Ortíz-Castro R, Díaz-Pérez C, Díaz-Pérez AL, Magaña-Dueñas V, López-Bucio J, Campos-García J (2017) Non-ribosomal peptide synthases from Pseudomonas aeruginosa play a role in cyclodipeptide biosynthesis, quorum-sensing regulation, and root development in a plant host. Microb Ecol 73:616-629

Götz-Rösch C, Sieper T, Fekete A, Schmitt-Kopplin P, Hartmann A, Schröder P (2015) Influence of bacterial N-acylhomoserine lactones on growth parameters, pigments, antioxidative capacities and the xenobiotic phase II detoxification enzymes in barley and yam bean. Front Plant Sci 6:205. https://doi.org/10.3389/fpls.2015.00205

Gray EJ, Lee KD, Souleimanov AM, Di Falco MR, Zhou X, Ly A, Charles TC, Driscoll BT, Smith DL (2006) A novel bacteriocin, thuricin 17 , produced by plant growth promoting rhizobacteria strain Bacillus thuringiensis NEB17: isolation and classification. J Appl Microbiol 100:545-554

*Gust AA, Willmann R, Desaki Y, Grabherr HM, Nürnberger T (2012) Plant LysM proteins: modules mediating symbiosis and immunity. Trends Plant Sci 17: 495-502

*Heil M, Bostock RM (2002) Induced systemic resistance (ISR) against pathogens in the context of induced plant defences. Ann Bot 89: 503-512

Huang C-J, Tsay J-F, Chang S-Y, Yang H-P, Wu W-S, Chen C-Y (2012) Dimethyl disulfide is an induced systemic resistance elicitor produced by Bacillus cereus C1L. Pest Manag Sci 68: 1306-1310

Iavicoli A, Boutet E, Buchala A, Métraux J-P (2003) Induced systemic resistance in Arabidopsis thaliana in response to root inoculation with Pseudomonas fluorescens CHA0. Mol Plant-Microbe Interact MPMI 16:851-858

Idris EE, Iglesias DJ, Talon M, Borriss R (2007) Tryptophandependent production of indole-3-acetic acid (IAA) affects 
level of plant growth promotion by Bacillus amyloliquefaciens FZB42. Mol Plant-Microbe Interact MPMI 20:619-626

Ismail AS, Valastyan JS, Bassler BL (2016) A host-produced autoinducer-2 mimic activates bacterial quorum sensing. Cell Host Microbe 19:470-480

Ji H, Dong H (2015) Key steps in type III secretion system (T3SS) towards translocon assembly with potential sensor at plant plasma membrane. Mol Plant Pathol 16:762-773

*Jones JDG, Dangl JL (2006) The plant immune system. Nature 444: 323-329

Jones KM, Sharopova N, Lohar DP, Zhang JQ, VandenBosch KA, Walker GC (2008) Differential response of the plant Medicago truncatula to its symbiont Sinorhizobium meliloti or an exopolysaccharide-deficient mutant. Proc Natl Acad Sci 105:704-709

Joseph CM, Phillips DA (2003) Metabolites from soil bacteria affect plant water relations. Plant Physiol Biochem 41:189-192

Kamilova F, Kravchenko LV, Shaposhnikov AI, Azarova T, Makarova N, Lugtenberg B (2006) Organic acids, sugars, and L-tryptophane in exudates of vegetables growing on stonewool and their effects on activities of rhizosphere bacteria. Mol Plant-Microbe Interact MPMI 19:250-256

*Karasov TL, Chae E, Herman JJ, Bergelson J (2017) Mechanisms to mitigate the trade-off between growth and defense. Plant Cell Online 29: 666-680

Khan W, Prithiviraj B, Smith DL (2008) Nod factor [Nod Bj $\mathrm{V}(\mathrm{C} 18: 1, \mathrm{MeFuc})]$ and lumichrome enhance photosynthesis and growth of corn and soybean. J Plant Physiol 165:1342-1351

Khan W, Costa C, Souleimanov A, Prithiviraj B, Smith DL (2011) Response of Arabidopsis thaliana roots to lipochitooligosaccharide from Bradyrhizobium japonicum and other chitin-like compounds. Plant Growth Regul 63:243-249

Kondorosi E, Gyuris J, Schmidt J, John M, Duda E, Hoffmann B, Schell J, Kondorosi A (1989) Positive and negative control of nod gene expression in Rhizobium meliloti is required for optimal nodulation. EMBO J 8:1331-1340

Ledger T, Rojas S, Timmermann T, Pinedo I, Poupin MJ, Garrido T, Richter P, Tamayo J, Donoso R (2016) Volatile-mediated effects predominate in Paraburkholderia phytofirmans growth promotion and salt stress tolerance of Arabidopsis thaliana. Front Microbiol 7:1838

Lee B, Farag MA, Park HB, Kloepper JW, Lee SH, Ryu C-M (2012) Induced resistance by a long-chain bacterial volatile: elicitation of plant systemic defense by a $\mathrm{C} 13$ volatile produced by Paenibacillus polymyxa. PLoS One 7(11):e48744. https://doi.org/10.1371/journal.pone.0048744

*Lewis K (2013) Platforms for antibiotic discovery. Nat Rev Drug Discov 12: 371-387

Liang Y, Cao Y, Tanaka K, Thibivilliers S, Wan J, Choi J, ho KC, Qiu J, Stacey G (2013) Nonlegumes respond to rhizobial Nod factors by suppressing the innate immune response. Science 341:1384-1387

*Liang Y, Tóth K, Cao Y, Tanaka K, Espinoza C, Stacey G (2014) Lipochitooligosaccharide recognition: an ancient story. New Phytol 204: 289-296

*Limpens E, van Zeijl A, Geurts R (2015) Lipochitooligosaccharides modulate plant host immunity to enable endosymbioses. Annu Rev Phytopathol 53: 311-334

Liu X-M, Zhang H (2015) The effects of bacterial volatile emissions on plant abiotic stress tolerance. Front Plant Sci 6:774

Liu F, Bian Z, Jia Z, Zhao Q, Song S (2012) The GCR1 and GPA1 participate in promotion of Arabidopsis primary root elongation induced by N-Acyl-homoserine lactones, the bacterial quorum-sensing signals. Mol Plant-Microbe Interact MPMI 25:677-683

*Liu L, Guo G, Wang Z, Ji H, Mu F, Li X (2014) Auxin in plant growth and stress responses. In: Tran L.-S.P., and Pal S. (eds) Phytohormones: a window to metabolism, signaling and biotechnological applications. Springer New York, p 1-35

*Lowery CA, Dickerson TJ, Janda KD (2008) Interspecies and interkingdom communication mediated by bacterial quorum sensing. Chem Soc Rev 37: 1337-1346

Ma Z, Hua GKH, Ongena M, Höfte M (2016) Role of phenazines and cyclic lipopeptides produced by Pseudomonas sp. CMR12a in induced systemic resistance on rice and bean. Environ Microbiol Rep 8:896-904. https://doi.org/10.1111 /1758-2229.12454

Marketon MM, Gronquist MR, Eberhard A, González JE (2002) Characterization of the Sinorhizobium meliloti $\sin \mathrm{R} / \mathrm{sin}$ I locus and the production of novel $\mathrm{N}$-acyl homoserine lactones. J Bacteriol 184:5686-5695

Marks BB, Megías M, Ollero FJ, Nogueira MA, Araujo RS, Hungria M (2015) Maize growth promotion by inoculation with Azospirillum brasilense and metabolites of Rhizobium tropici enriched on lipo-chitooligosaccharides (LCOs). AMB Express 5:71

*Martinez-Medina A, Flors V, Heil M, Mauch-Mani B, Pieterse CMJ, Pozo MJ, Ton J, van Dam NM, Conrath U (2016) Recognizing plant defense priming. Trends Plant Sci 21: 818-822

Marulanda A, Barea J-M, Azcón R (2009) Stimulation of plant growth and drought tolerance by native microorganisms (AM fungi and bacteria) from dry environments: mechanisms related to bacterial effectiveness. J Plant Growth Regul 28:115-124

Mathesius U, Mulders S, Gao M, Teplitski M, Caetano-Anolles G, Rolfe BG, Bauer WD (2003) Extensive and specific responses of a eukaryote to bacterial quorum-sensing signals. Proc Natl Acad Sci U S A 100:1444-1449

Maurhofer M, Reimmann C, Schmidli-Sacherer P, Heeb S, Haas D, Défago G (1998) Salicylic acid biosynthetic genes expressed in Pseudomonas fluorescens strain P3 improve the induction of systemic resistance in tobacco against tobacco necrosis virus. Phytopathology 88:678-684

Maymon M, Martínez-Hidalgo P, Tran SS, Ice T, Craemer K, Anbarchian T, Sung T, Hwang LH, Chou M, Fujishige NA, Villella W, Ventosa J, Sikorski J, Sanders ER, Faull KF, Hirsch AM (2015) Mining the phytomicrobiome to understand how bacterial coinoculations enhance plant growth. Front Plant Sci 6:784

Medeiros FHV, Souza RM, Medeiros FCL, Zhang H, Wheeler T, Payton P, Ferro HM, Paré PW (2011) Transcriptional profiling in cotton associated with Bacillus subtilis (UFLA285) induced biotic-stress tolerance. Plant Soil 347:327-337

Mendes R, Kruijt M, de BI, Dekkers E, van der VM, Schneider JHM, Piceno YM, DeSantis TZ, Andersen GL, Bakker PAHM, Raajimakers JM (2011) Deciphering the rhizosphere 
microbiome for disease-suppressive bacteria. Science 332: $1097-1100$

Meziane H, Van Der Sluis I, Van Loon LC, Höfte M, Bakker PAHM (2005) Determinants of Pseudomonas putida WCS358 involved in inducing systemic resistance in plants. Mol Plant Pathol 6:177-185

Miao C, Liu F, Zhao Q, Jia Z, Song S (2012) A proteomic analysis of Arabidopsis thaliana seedling responses to 3-oxooctanoyl-homoserine lactone, a bacterial quorum-sensing signal. Biochem Biophys Res Commun 427:293-298

*Mickelbart MV, Hasegawa PM, Bailey-Serres J (2015) Genetic mechanisms of abiotic stress tolerance that translate to crop yield stability. Nat Rev Genet 16: 237-251

Millet YA, Danna CH, Clay NK, Songnuan W, Simon MD, Werck-Reichhart D, Ausubel FM (2010) Innate immune responses activated in Arabidopsis roots by microbeassociated molecular patterns. Plant Cell Online 22:973-990

Mitra RM, Long SR (2004) Plant and bacterial symbiotic mutants define three transcriptionally distinct stages in the development of the Medicago truncatula/Sinorhizobium meliloti symbiosis. Plant Physiol 134:595-604

Nihorimbere V, Cawoy H, Seyer A, Brunelle A, Thonart P, Ongena M (2012) Impact of rhizosphere factors on cyclic lipopeptide signature from the plant beneficial strain Bacillus amyloliquefaciens S499. FEMS Microbiol Ecol 79:176-191

Okazaki S, Kaneko T, Sato S, Saeki K (2013) Hijacking of leguminous nodulation signaling by the rhizobial type III secretion system. Proc Natl Acad Sci U S A 110: 17131-17136

Oláh B, Brière C, Bécard G, Dénarié J, Gough C (2005) Nod factors and a diffusible factor from arbuscular mycorrhizal fungi stimulate lateral root formation in Medicago truncatula via the DMI1/DMI2 signaling pathway. Plant J Cell Mol Biol 44:195-207

*Olanrewaju OS, Glick BR, Babalola OO (2017) Mechanisms of action of plant growth promoting bacteria. World J Microbiol Biotechnol 33: 197

*Oldroyd GED (2013) Speak, friend, and enter: signaling systems that promote beneficial symbiotic associations in plants. Nat Rev Microbiol 11: 252-263

*Oldroyd GED, Murray JD, Poole PS, Downie JA (2011) The rules of engagement in the legume-rhizobial symbiosis. Annu Rev Genet 45: 119-144

*Ongena M, Jacques P (2008) Bacillus lipopeptides: versatile weapons for plant disease biocontrol. Trends Microbiol 16: $115-125$

Ongena M, Jourdan E, Adam A, Paquot M, Brans A, Joris B, Arpigny J-L, Thonart P (2007) Surfactin and fengycin lipopeptides of Bacillus subtilis as elicitors of induced systemic resistance in plants. Environ Microbiol 9:1084-1090

Ortíz-Castro R, Martínez-Trujillo M, López-Bucio J (2008) Nacyl-L-homoserine lactones: a class of bacterial quorumsensing signals alter post-embryonic root development in Arabidopsis thaliana. Plant Cell Environ 31:1497-1509

Ortíz -Castro R, Díaz-Pérez C, Martínez-Trujillo M, del Río RE, Campos-García J, López-Bucio J (2011) Transkingdom signaling based on bacterial cyclodipeptides with auxin activity in plants. Proc Natl Acad Sci U S A 108:7253-7258

Oslizlo A, Stefanic P, Vatovec S, Beigot Glaser S, Rupnik M, Mandic-Mulec I (2015) Exploring ComQXPA quorum-sensing diversity and biocontrol potential of
Bacillus spp. isolates from tomato rhizoplane. Microb Biotechnol 8:527-540

Park Y-G, Mun B-G, Kang S-M, Hussain A, Shahzad R, Seo C-W, Kim A-Y, Lee S-U, Oh KY, Lee DY, Lee IJ, Yun BW (2017) Bacillus aryabhattai SRB02 tolerates oxidative and nitrosative stress and promotes the growth of soybean by modulating the production of phytohormones. PLoS One 12:e0173203. https://doi.org/10.1371/journal.pone.0173203

*Paterson J, Jahanshah G, Li Y, Wang Q, Mehnaz S, Gross $\mathrm{H}$ (2017) The contribution of genome mining strategies to the understanding of active principles of PGPR strains. FEMS Microbiol Ecol 93: 1-31. https://doi. org/10.1093/femsec/fiw249

*Pel MJC, Pieterse CMJ (2013) Microbial recognition and evasion of host immunity. J Exp Bot 64: 1237-1248

Pereira CS, McAuley JR, Taga ME, Xavier KB, Miller ST (2008) Sinorhizobium meliloti, a bacterium lacking the autoinducer2 (AI-2) synthase, responds to AI-2 supplied by other bacteria. Mol Microbiol 70:1223-1235

*Pierson LS, Wood DW, Pierson EA (1998) Homoserine lactonemediated gene regulation in plant-associated bacteria. Annu Rev Phytopathol 36: 207-225

Pieterse CM, van Wees SC, van Pelt JA, Knoester M, Laan R, Gerrits H, Weisbeek PJ, van Loon LC (1998) A novel signaling pathway controlling induced systemic resistance in Arabidopsis. Plant Cell 10:1571-1580

*Pieterse CMJ, Van der Does D, Zamioudis C, Leon-Reyes A, Van Wees SCM (2012) Hormonal modulation of plant immunity. Annu Rev Cell Dev Biol 28: 489-521

*Pieterse CMJ, Zamioudis C, Berendsen RL, Weller DM, Van Wees SCM, Bakker PAHM (2014) Induced systemic resistance by beneficial microbes. Annu Rev Phytopathol 52: 347-375

*Prashar P, Kapoor N, Sachdeva S (2013) Rhizosphere: its structure, bacterial diversity and significance. Rev Environ Sci Biotechnol 13: 63-77

Prithiviraj B, Zhou X, Souleimanov A, Khan WM, Smith DL, Kahn WM (2003) A host-specific bacteria-to-plant signal molecule (Nod factor) enhances germination and early growth of diverse crop plants. Planta 216:437-445

*Raaijmakers JM, De Bruijn I, Nybroe O, Ongena M (2010) Natural functions of lipopeptides from Bacillus and Pseudomonas: more than surfactants and antibiotics. FEMS Microbiol Rev 34: 1037-1062

von Rad U, Klein I, Dobrev PI, Kottova J, Zazimalova E, Fekete A, Hartmann A, Schmitt-Kopplin P, Durner J (2008) Response of Arabidopsis thaliana to N-hexanoyl-DLhomoserine-lactone, a bacterial quorum sensing molecule produced in the rhizosphere. Planta 229:73-85

Rahman A, Uddin W, Wenner NG (2015) Induced systemic resistance responses in perennial ryegrass against Magnaporthe oryzae elicited by semi-purified surfactin lipopeptides and live cells of Bacillus amyloliquefaciens. Mol Plant Pathol 16:546-558

Rey T, Nars A, Bonhomme M, Bottin A, Huguet S, Balzergue S, Jardinaud M-F, Bono J-J, Cullimore J, Dumas B, Gough C, Jacquet C (2013) NFP, a LysM protein controlling Nod factor perception, also intervenes in Medicago truncatula resistance to pathogens. New Phytol 198:875-886 
Rose CM, Venkateshwaran M, Volkening JD, Grimsrud PA, Maeda J, Bailey DJ, Park K, Howes-Podoll M, den OD, Yeun LH, Westphall MA, Sussman MR, Ané JM, Coon JJ (2012) Rapid phosphoproteomic and transcriptomic changes in the rhizobia-legume symbiosis. Mol Cell Proteomics 11:724-744

*Rubio V, Bustos R, Irigoyen ML, Cardona-López X, RojasTriana M, Paz-Ares J (2009) Plant hormones and nutrient signaling. Plant Mol Biol 69: 361-373

Rudrappa T, Biedrzycki ML, Kunjeti SG, Donofrio NM, Czymmek KJ, Paré PW, Bais HP (2010) The rhizobacterial elicitor acetoin induces systemic resistance in Arabidopsis thaliana. Commun Integr Biol 3:130-138

Ryu C-M, Farag MA, Hu C-H, Reddy MS, Kloepper JW, Paré PW (2004) Bacterial volatiles induce systemic resistance in Arabidopsis. Plant Physiol 134:1017-1026

Salomon MV, Bottini R, de Souza Filho GA, Cohen AC, Moreno D, Gil M, Piccoli P (2014) Bacteria isolated from roots and rhizosphere of Vitis vinifera retard water losses, induce abscisic acid accumulation and synthesis of defense-related terpenes in in vitro cultured grapevine. Physiol Plant 151:359-374

Schauder S, Shokat K, Surette MG, Bassler BL (2001) The LuxS family of bacterial autoinducers: biosynthesis of a novel quorum-sensing signal molecule. Mol Microbiol 41:463-476

Schenk ST, Hernández-Reyes C, Samans B, Stein E, Neumann C, Schikora M, Reichelt M, Mithöfer A, Becker A, Kogel K-H, Schikora A (2014) N-acyl-homoserine lactone primes plants for cell wall reinforcement and induces resistance to bacterial pathogens via the salicylic acid/oxylipin pathway. Plant Cell 26:2708-2723

Schikora A, Schenk ST, Stein E, Molitor A, Zuccaro A, Kogel K$\mathrm{H}$ (2011) N-acyl-homoserine lactone confers resistance toward biotrophic and hemibiotrophic pathogens via altered activation of AtMPK6. Plant Physiol 157:1407-1418

*Schikora A, Schenk ST, Hartmann A (2016). Beneficial effects of bacteria-plant communication based on quorum sensing molecules of the $\mathrm{N}$-acyl homoserine lactone group. Plant Mol Biol 90: 605-612

*Schlaeppi K, Bulgarelli D (2015) The plant microbiome at work. Mol Plant-Microbe Interact MPMI 28: 212-217

Schuhegger R, Ihring A, Gantner S, Bahnweg G, Knappe C, Vogg G, Hutzler P, Schmid M, Van Breusegem F, Eberl L, Hartmann A, Langebartels C (2006) Induction of systemic resistance in tomato by N-acyl-L-homoserine lactoneproducing rhizosphere bacteria. Plant Cell Environ 29:909918

Somers E, Ptacek D, Gysegom P, Srinivasan M, Vanderleyden J (2005) Azospirillum brasilense produces the auxin-like phenylacetic acid by using the key enzyme for indole-3acetic acid biosynthesis. Appl Environ Microbiol 71: $1803-1810$

Souleimanov A, Prithiviraj B, Smith DL (2002) The major Nod factor of Bradyrhizobium japonicum promotes early growth of soybean and corn. J Exp Bot 53:1929-1934

*Spaepen S (2015) Plant hormones produced by microbes. In: Lugtenberg B. (ed) Principles of plant-microbe interactions. Springer International Publishing, p 247-256

*Spaepen S, Vanderleyden J (2011) Auxin and plant-microbe interactions. Cold Spring Harb Perspect Biol 3: a001438
*Staehelin C, Krishnan HB (2015) Nodulation outer proteins: double-edged swords of symbiotic rhizobia. Biochem J 470: 263-274

Stintzi A, Evans K, Meyer J, Poole K (1998) Quorum-sensing and siderophore biosynthesis in Pseudomonas aeruginosa: lasRllasI mutants exhibit reduced pyoverdine biosynthesis. FEMS Microbiol Lett 166:341-345

*Stokes ME, McCourt P (2014) Towards personalized agriculture: what chemical genomics can bring to plant biotechnology. Front Plant Sci 5: 344

Subramanian S, Souleimanov A, Smith DL (2016) Proteomic studies on the effects of lipo-chitooligosaccharide and thuricin 17 under unstressed and salt stressed conditions in Arabidopsis thaliana. Front Plant Sci 7:1314

*Tabashnik BE, Brévault T, Carrière Y (2013) Insect resistance to Bt crops: lessons from the first billion acres. Nat Biotechnol 31: $510-521$

*Takatsuji H (2017) Regulating tradeoffs to improve rice production. Front Plant Sci 8: 171

Tanaka K, Cho S-H, Lee H, Pham AQ, Batek JM, Cui S, Qiu J, Khan SM, Joshi T, Zhang ZJ, Dong X, Stacey G (2015) Effect of lipo-chitooligosaccharide on early growth of $\mathrm{C} 4$ grass seedlings. J Exp Bot 66:5727-5738

Tashiro Y, Yawata Y, Toyofuku M, Uchiyama H, Nomura N (2013) Interspecies interaction between Pseudomonas aeruginosa and other microorganisms. Microbes Environ JSME 28:13-24

Teplitski M, Eberhard A, Gronquist MR, Gao M, Robinson JB, Bauer WD (2003) Chemical identification of N-acyl homoserine lactone quorum-sensing signals produced by Sinorhizobium meliloti strains in defined medium. Arch Microbiol 180:494-497

*Thaler JS, Humphrey PT, Whiteman NK (2012) Evolution of jasmonate and salicylate signal crosstalk. Trends Plant Sci 17: $260-270$

*Thomashow LS, Weller DM (1996) Current concepts in the use of introduced bacteria for biological disease control: mechanisms and antifungal metabolites. In: Stacey G., and Keen N.T. (eds) Plant-microbe interactions. Springer US), p 187-235

*Timmusk S, Behers L, Muthoni J, Muraya A, Aronsson A-C (2017) Perspectives and challenges of microbial application for crop improvement. Front Plant Sci 8: 49

Trapet P, Avoscan L, Klinguer A, Pateyron S, Citerne S, Chervin C, Mazurier S, Lemanceau P, Wendehenne D, Besson-Bard A (2016) The Pseudomonas fluorescens siderophore pyoverdine weakens Arabidopsis thaliana defense in favor of growth in iron-deficient conditions. Plant Physiol 171:675-693

*Udvardi M, Poole PS (2013) Transport and metabolism in legume-rhizobia symbioses. Annu Rev Plant Biol 64: $781-805$

*Vandenkoornhuyse P, Quaiser A, Duhamel M, Le Van A, Dufresne A (2015) The importance of the microbiome of the plant holobiont. New Phytol 206: 1196-1206

Vansuyt G, Robin A, Briat J-F, Curie C, ad Lemanceau P (2007) Iron acquisition from Fe-pyoverdine by Arabidopsis thaliana. Mol Plant-Microbe Interact MPMI 20:441-447

Veliz-Vallejos DF, van Noorden GE, Yuan M, Mathesius U (2014) A Sinorhizobium meliloti-specific $\mathrm{N}$-acyl homoserine lactone quorum-sensing signal increases nodule numbers in 
Medicago truncatula independent of autoregulation. Front Plant Sci 5:551

*Venturi V, Fuqua C (2013) Chemical signaling between plants and plant-pathogenic bacteria. Annu Rev Phytopathol 51: $17-37$

Verhagen BWM, Glazebrook J, Zhu T, Chang H-S, van Loon LC, Pieterse CMJ (2004) The transcriptome of rhizobacteriainduced systemic resistance in Arabidopsis. Mol PlantMicrobe Interact MPMI 17: 895-908

*Verma V, Ravindran P, Kumar PP (2016) Plant hormonemediated regulation of stress responses. BMC Plant Biol 16: 86

Wang H, Yang X, Guo L, Zeng H, Qiu D (2015) PeBL1, a novel protein elicitor from Brevibacillus laterosporus strain A60, activates defense responses and systemic resistance in Nicotiana benthamiana. Appl Environ Microbiol 81:2706-2716

Wang N, Liu M, Guo L, Yang X, Qiu D (2016) A novel protein elicitor (PeBA1) from Bacillus amyloliquefaciens NC6 induces systemic resistance in tobacco. Int J Biol Sci 12:757-767

Weller DM, Landa BB, Mavrodi OV, Schroeder KL, De La Fuente L, Blouin Bankhead S, Allende Molar R, Bonsall RF, Mavrodi DV, Thomashow LS (2007) Role of 2,4diacetylphloroglucinol-producing fluorescent Pseudomonas spp. in the defense of plant roots. Plant Biol Stuttg Ger 9:4-20

Weller DM, Mavrodi DV, van Pelt JA, Pieterse CMJ, van Loon LC, Bakker PAHM (2012) Induced systemic resistance in Arabidopsis thaliana against Pseudomonas syringae pv. tomato by 2,4-diacetylphloroglucinol-producing Pseudomonas fluorescens. Phytopathology 102:403-412

*Werner GDA, Cornwell WK, Sprent JI, Kattge J, Kiers ET (2014) A single evolutionary innovation drives the deep evolution of symbiotic N2-fixation in angiosperms. Nat Commun 5: 4087

*Wiesel L, Newton AC, Elliott I, Booty D, Gilroy EM, Birch PRJ, Hein I (2014) Molecular effects of resistance elicitors from biological origin and their potential for crop protection. Front Plant Sci 5: 655

*Yang J, Kloepper JW, Ryu C-M (2009) Rhizosphere bacteria help plants tolerate abiotic stress. Trends Plant Sci 14: 1-4

*Yanhui C, Xiaoyuan Y, Kun H, Meihua L, Jigang L, Zhaofeng G, Zhiqiang L, Yunfei Z, Xiaoxiao W, Xiaoming Q, Yunping S, Li Z, Xiaohui D, Jingchu L, Xing-Wang D, Zhangliang C, Hongya G, Li-Jia Q (2006) The MYB transcription factor superfamily of Arabidopsis: expression analysis and phylogenetic comparison with the rice MYB family. Plant Mol Biol 60: 107-124

Zamioudis C, Korteland J, Van Pelt JA, van Hamersveld M, Dombrowski N, Bai Y, Hanson J, Van Verk MC, Ling H-Q,
Schulze-Lefert P, Pieterse CM (2015) Rhizobacterial volatiles and photosynthesis-related signals coordinate MYB72 expression in Arabidopsis roots during onset of induced systemic resistance and iron-deficiency responses. Plant $\mathrm{J}$ Cell Mol Biol 84:309-322

Zarkani AA, Stein E, Röhrich CR, Schikora M, EvguenievaHackenberg E, Degenkolb T, Vilcinskas A, Klug G, Kogel K-H, Schikora A (2013) Homoserine lactones influence the reaction of plants to rhizobia. Int J Mol Sci 14:17122-17146

van Zeijl A, Op den Camp RHM, Deinum EE, Charnikhova T, Franssen H, Op den Camp HJM, Bouwmeester H, Kohlen W, Bisseling T, Geurts R (2015) Rhizobium lipo-chitooligosaccharide signaling triggers accumulation of cytokinins in Medicago truncatula roots. Mol Plant 8:1213-1226

Zhang H, Kim M-S, Sun Y, Dowd SE, Shi H, Paré PW (2008) Soil bacteria confer plant salt tolerance by tissue-specific regulation of the sodium transporter HKT1. Mol Plant-Microbe Interact MPMI 21:737-744

Zhang H, Sun Y, Xie X, Kim M-S, Dowd SE, Paré PW (2009) A soil bacterium regulates plant acquisition of iron via deficiency-inducible mechanisms. Plant J Cell Mol Biol 58:568-577

Zhang L, Chen X-J, Lu H-B, Xie Z-P, Staehelin C (2011) Functional analysis of the type 3 effector nodulation outer protein L (NopL) from Rhizobium sp. NGR234: symbiotic effects, phosphorylation, and interference with mitogen-activated protein kinase signaling. J Biol Chem 286:32178-32187

Zhao Q, Zhang C, Jia Z, Huang Y, Li H, Song S (2014) Involvement of calmodulin in regulation of primary root elongation by N-3-oxo-hexanoyl homoserine lactone in Arabidopsis thaliana. Front Plant Sci 5:807

Zhao Q, Li M, Jia Z, Liu F, Ma H, Huang Y, Song S (2016) AtMYB44 positively regulates the enhanced elongation of primary roots induced by N-3-oxo-hexanoyl-homoserine lactone in Arabidopsis thaliana. Mol Plant-Microbe Interact MPMI 29:774-785

Zhou C, Guo J, Zhu L, Xiao X, Xie Y, Zhu J, Ma Z, Wang J (2016) Paenibacillus polymyxa BFKC01 enhances plant iron absorption via improved root systems and activated iron acquisition mechanisms. Plant Physiol Biochem PPB 105:162-173

Zhou C, Zhu L, Xie Y, Li F, Xiao X, Ma Z, Wang J (2017) Bacillus licheniformis SA03 confers increased saline-alkaline tolerance in Chrysanthemum plants by induction of abscisic acid accumulation. Front Plant Sci 8:1143

*Zilber-Rosenberg I, Rosenberg E (2008) Role of microorganisms in the evolution of animals and plants: the hologenome theory of evolution. FEMS Microbiol Rev 32: 723-735 